\title{
Recent developments in advanced anode materials for lithium-ion batteries
}

\author{
Hui Chang ${ }^{1, \#}$, Yu-Rong Wu ${ }^{2, *}$, Xiao Han ${ }^{2}$, Ting-Feng $\mathrm{Yi}^{1,3,4}$ \\ 'School of Materials Science and Engineering, Northeastern University, Shenyang 110819, Liaoning, China. \\ ${ }^{2}$ School of Chemistry and Chemical Engineering, Anhui University of Technology, Maanshan 243002, Anhui, China. \\ ${ }^{3}$ School of Resources and Materials, Northeastern University at Qinhuangdao, Qinhuangdao 066004, Hebei, China. \\ ${ }^{4}$ Key Laboratory of Dielectric and Electrolyte Functional Material Hebei Province, Qinhuangdao 066004, Hebei, China. \\ \#Authors contributed equally.
}

Correspondence to: Prof. Ting-Feng Yi, School of Materials Science and Engineering, Northeastern University, No. 3-11, Wenhua Road, Heping District, Shenyang 110819, Liaoning, China; School of Resources and Materials, Northeastern University at Qinhuangdao, No. 143 Taishan Road, Qinhuangdao 066004, Hebei, China; Key Laboratory of Dielectric and Electrolyte Functional Material Hebei Province, No. 143 Taishan Road, Qinhuangdao 066004, Hebei, China. E-mail: yitingfeng@neuq.edu.cn

How to cite this article: Chang H, Wu YR, Han X, Yi TF. Recent developments in advanced anode materials for lithium-ion batteries. Energy Mater 2021;1:100003. https://dx.doi.org/10.20517/energymater.2021.02

Received: 1 Jul 2021 First Decision: 3 Aug 2021 Revised: 15 Aug 2021 Accepted: 7 Sep 2021 First online: 7 Sep 2021

Academic Editor: Yuping Wu Copy Editor: Yue-Yue Zhang Production Editor: Yue-Yue Zhang

\begin{abstract}
The rapid expansion of electric vehicles and mobile electronic devices is the main driver for the improvement of advanced high-performance lithium-ion batteries (LIBs). The electrochemical performance of LIBs depends on the specific capacity, rate performance and cycle stability of the electrode materials. In terms of the enhancement of LIB performance, the improvement of the anode material is significant compared with the cathode material. There are still some challenges in producing an industrial anode material that is superior to commercial graphite. Based on the different electrochemical reaction mechanisms of anode materials for LIBs during charge and discharge, the advantages/disadvantages and electrochemical reaction mechanisms of intercalation-, conversion- and alloyingtype anode materials are summarized in detail here. The methods and strategies for improving the electrochemical performance of different types of anode materials are described in detail. Finally, challenges for the future development of LIBs are also considered. This review offers a meaningful reference for the construction and performance optimization of anode materials for LIBs.
\end{abstract}

Keywords: Anode, lithium-ion battery, intercalation, conversion, alloying 


\section{INTRODUCTION}

With the decline of oil and other traditional energy sources, the development and utilization of renewable energy sources, such as solar, wind and tidal power, have become critical problems to be solved in the new $\operatorname{era}^{[1-3]}$. However, these new energy supplies are unstable and cannot be used continuously, so they need to be converted into electricity before being exported ${ }^{[4]}$. Research into rechargeable batteries has therefore become especially important ${ }^{[5-7]}$. Traditional lead-acid, nickel-cadmium and nickel-metal hydride batteries have some disadvantages, such as short service life, low energy density and environmental pollution, which greatly limit their large-scale application ${ }^{[8-11]}$. The development of rechargeable batteries to replace these traditional batteries has been the main priority of the battery industry in recent decades ${ }^{[12-14]}$. Therefore, there is an urgent need to develop non-toxic and pollution-free battery electrode materials and separators.

Compared with traditional batteries, Li-ion batteries (LIBs) already dominate the development of electronic products and show superior development prospects due to their small size, lightweight, high working voltage, high energy density, good cycling performance, lack of memory effect and environmental friendlines ${ }^{[15-17]}$. LIBs have been widely used in smartphones, laptops and other portable electronic devices since the 20th century ${ }^{[18-20]}$. Currently, LIBs are used as the main power supply of electric vehicles but they still require higher energy density, lower costs and enhanced environmental performance ${ }^{[21-23]}$. The lithiumion shuttle between the anode and the cathode forms the basis of a LIB as the power supply, and the $\mathrm{Li}^{+}$ insertion ability of the anode is the main factor that determines its performance ${ }^{[24-27]}$. In order to maintain the development of advanced anode materials, it is becoming ever more necessary to develop high-capacity anode materials to improve the performance of the overall $\mathrm{LIB}^{[28-31]}$.

Graphite has been the main LIB anode material since its commercialization by Sony in $1991^{[32,33]}$. The reason for this is that graphite has numerous advantages, such as low cost, absolute abundance, non-toxicity and structural stability ${ }^{[1934-36]}$. However, the theoretical capacity of graphite is low, which limits its feasibility for high-power applications ${ }^{[37-39]}$. It is also found that the delithiation/lithiation in the cycle process cause a volume change in the material, which produces stress on the electrode and is not conducive to cycling stability ${ }^{[40-42]}$. In addition, the graphite electrode may react with the electrolyte at low operating voltages, resulting in lithium deposition ${ }^{[4-45]}$. This phenomenon not only reduces battery performance, but also poses a serious safety hazard. Therefore, the study of alternative anode materials to improve the electrochemical properties of LIBs, such as specific capacity, cycle stability and safety, is essential. After decades of continuous research, a variety of different types of anode materials have been discovered and improved. So far, according to the different reaction mechanisms, LIB anode materials can be divided into the following three types: intercalation (e.g., graphite ${ }^{[4,47]}$ and lithium titanate ${ }^{[48,4]}$ ), conversion (e.g., transition metal oxides $^{[50,51]}$ and sulfides ${ }^{[52]}$ ) and alloying anode materials (e.g., silicon ${ }^{[53]}, \operatorname{tin}^{[54]}$, germanium ${ }^{[55]}$ and antimony ${ }^{[56]}$.

The earliest anode material considered for LIBs was lithium metal. However, lithium dendrites can be formed during the reaction process, thereby limiting its commercialization. In the review, recent advances in the different electrochemical reaction mechanisms of LIB anode materials are summarized, as summarized in Scheme 1. We provide a comprehensive report and in-depth discussion of the electrochemical reactions of anode materials, as well as the advantages and challenges of each type of anode material. The corresponding optimization strategies are also described in detail. This review represents an important reference for the construction and optimization of high-performance anode materials.

\section{INTERCALATION-TYPE ANODE MATERIALS}

The reaction mechanism for intercalation-type anode materials is based on the intercalation and 


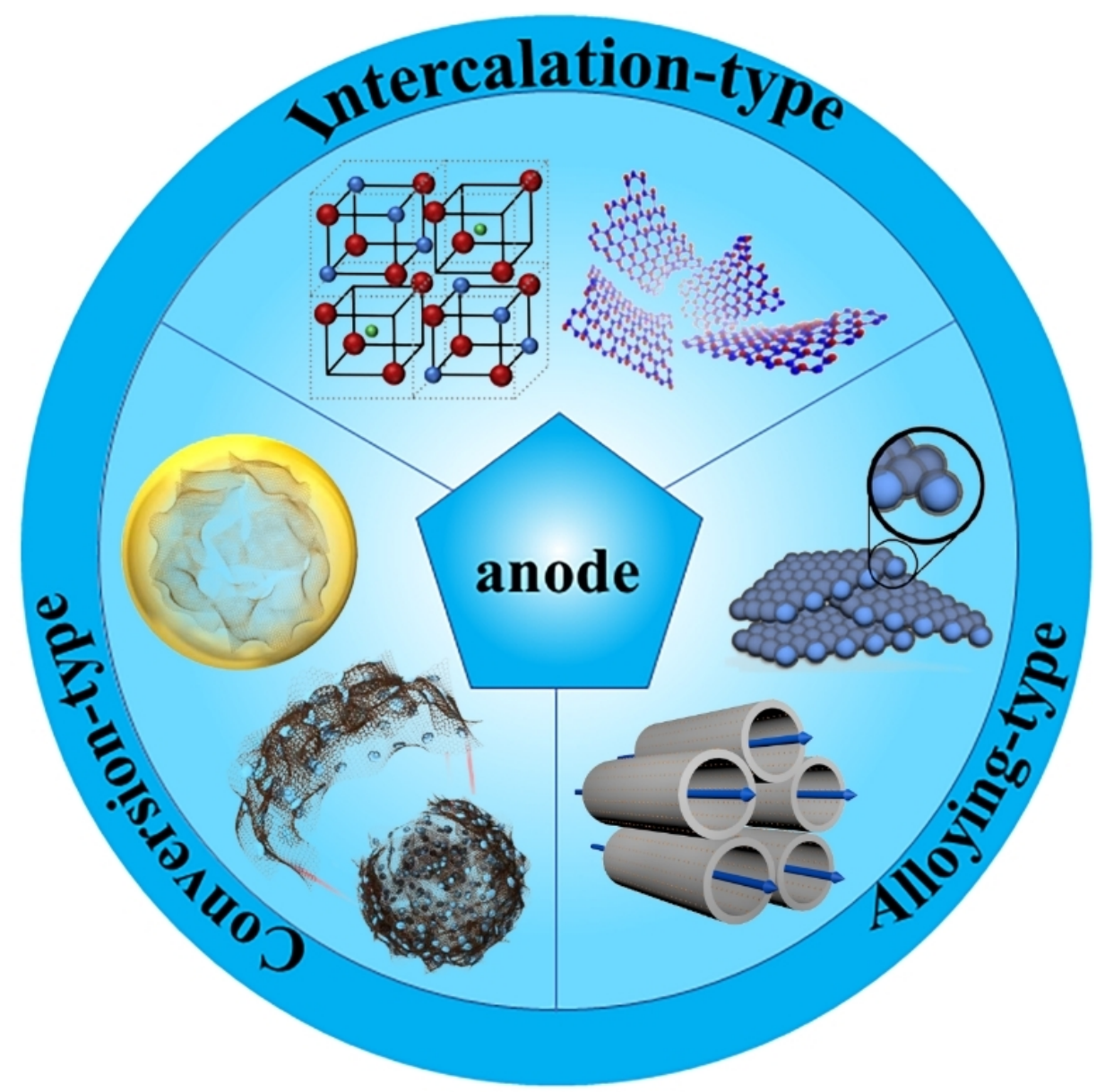

Scheme 1. Schematic of the three main types of anode material for lithium-ion batteries (LIBs).

deintercalation of lithium ions in the crystal lattice of the host material. Such LIBs are also known as rocking-chair batteries ${ }^{[57-59]}$. As a layered carbon material, graphite was the first commercialized LIB anode material and is also the most well-known ${ }^{[6,66]}$. Layered $\mathrm{LiC}_{6}$ can be formed by intercalating lithium ions. The discharge plateau of $\mathrm{LiC}_{6}$ is below $0.2 \mathrm{~V}\left(v s . \mathrm{Li}^{+} / \mathrm{Li}\right)$ and it has outstanding dynamic performance for the intercalation of lithium ${ }^{[5,62,63]}$. However, because of the slow diffusion rate of lithium ions, the rate performance of graphite is not ideal. The intercalated lithium potential is similar to the stripping potential of lithium metal and therefore lithium dendrites and solid electrolyte interphase (SEI) films can easily form $^{[64,65]}$. In addition, the miscibility of the solution with an electrolyte makes the organic solvent and lithium insert into the graphite layer, causing the graphite to peel off gradually. These problems are not favorable in practical applications. There are two main methods to improve the electrochemical performance of graphite anodes, namely, accelerating the diffusion of lithium ions into graphite and the entire electrode and enhancing the interfacial reaction between graphite and electrolyte to form a thinner and more stable SEI layer.

Cheng et al. ${ }^{[6]}$ prepared a multichannel graphite anode with channels etched into the graphite surface, which enabled the rapid entry of lithium ions into graphite particles for the rapid charging of LIBs. This structure can improve the accessibility of these ions inside the graphite and has good coulombic efficiency. Their results showed that the multichannel graphite anode exhibits excellent charge rate capacities of $83 \%$ and $73 \%$ at $6 \mathrm{C}$ and $10 \mathrm{C}$, respectively, which are much better than the pristine graphite anode. In addition, 
multichannel graphite anodes exhibit a higher enhanced discharge rate capability than pristine graphite. In addition, it has excellent cycling stability with a capacity retention rate of $85 \%$ after 3000 cycles at $6 \mathrm{C}$ without any additives.

Son et al. ${ }^{[63]}$ systematically studied the thermal exfoliation of expandable graphite (EG) in order to increase its interlayer spacing distance and to determine the optimal temperature for volume expansion. As shown in Figure 1A, all the EG samples exhibit a worm-like morphology with rich open/semi-open inner pore structures. In particular, at the heat treatment temperature of $600{ }^{\circ} \mathrm{C}$ for a period of $30 \mathrm{~min}$ (EG30), there is a maximum shrinkage of $3.37 \AA$ of d-spacing and a crystallite size of $20.96 \mathrm{~nm}$, while maintaining a similar long range-ordered graphite layer/sheet. In addition, EG30 shows excellent performance in LIBs, with a very high average reversible specific capacity of $338 \mathrm{mAh} \cdot \mathrm{g}^{-1}$ at $100 \mathrm{~m} \cdot \mathrm{Ag}^{-1}$ and a high rate capacity of $112 \mathrm{~mA} \cdot \mathrm{h} \mathrm{g}^{-1}$ at $3 \mathrm{~A} \mathrm{~g} \mathrm{~g}^{-1}$ [Figure 1B]. The excellent battery performance of EG30 is attributed to its unique turbostratically arranged graphitic nanolayers/nanosheets, the range of chemical environments resulting from the distribution of redox-active sites in the pores at the defect sites, the minimum nanocrystal size and the possible formation of LiC72 compound. This finding could provide an inspiration for the construction and development of high-performance graphite electrodes for practical applications in LIBs.

Surface modification is an effective method to improve the rapid charging ability of graphite anode materials. Kim et al.$^{[65]}$ improved the rapid charging ability of graphite anode materials by modifying $\mathrm{Al}_{2} \mathrm{O}_{3}$ on the surface of graphite. As shown in Figure 1C, the 1 wt.\% $\mathrm{Al}_{2} \mathrm{O}_{3} @$ graphite electrode retains a reversible capacity of $\sim 337.1 \mathrm{mAh} \cdot \mathrm{g}^{-1}$ at a high charge rate of $4000 \mathrm{~mA} \mathrm{~g}{ }^{-1}$, which corresponds to $97.2 \%$ of the capacity obtained at $100 \mathrm{~mA} \mathrm{~g}^{-1}$. The full battery test with a $\mathrm{LiCoO}_{2}$ cathode and $\mathrm{Al}_{2} \mathrm{O}_{3}$-coated graphite anode proves that the introduction of amorphous $\mathrm{Al}_{2} \mathrm{O}_{3}$ improves the fast charging ability of the graphite anode material. This method is a practical way of enhancing the fast charging ability of graphite anode materials for highpower LIBs.

Similar to graphite, hard carbon (non-graphitized carbon) materials also belong to the intercalation type of anode material. Their layer spacing is generally greater than $3.8 \AA$, more than twice the diameter of $\mathrm{Li}^{+}$ $(1.52 \AA)^{[31,66]}$. This large channel is conducive to the diffusion of $\mathrm{Li}^{+}$and rapid charge and discharge. Therefore, it provides high capacity and good rate performance. However, although hard carbon has a higher voltage platform than graphite, it has voltage hysteresis and a high initial irreversible capacity, which is why graphite has not been replaced as the mainstream anode material ${ }^{[67-69]}$. It is noteworthy that the transport of $\mathrm{Li}^{+}$is mainly dependent on the structure of the material. It was realized that the presence of defects accelerates the diffusion of $\mathrm{Li}^{+}$and so the subsequent emergence of carbon materials with unique structures, such as graphene $e^{[70-72]}$, nanofibers ${ }^{[73-75]}$ and nanotubes ${ }^{[76-78]}$, has occurred.

Ai et al. ${ }^{[72]}$ prepared N and S co-doped graphene (NS-G). The initial discharge capacity of the obtained material is $1636 \mathrm{mAh} \cdot \mathrm{g}^{-1}$. After 500 cycles, the electrode still offers a reversible capacity of $1090 \mathrm{mAh} \cdot \mathrm{g}^{-1}$. As the number of cycles increases, the capacity of the NS-G anode increases gradually; this can be ascribed to the enhancement of the sample properties of lithium ions. The difference in electronegativity and size between the doped and carbon atoms results in changes in the internal structure (the formation of topological defects) and charge density of the graphene, thereby enhancing the electrochemical performance of the material.

Wang et al. ${ }^{[73]}$ synthesized P-doped mesoporous carbon with a high P content and large pore size through evaporation-induced self-assembly. Tricresyl phosphate was used as a phosphorus precursor, a phenolic solution was used as a carbon precursor, the triblock copolymer F127 was used as a soft template and 

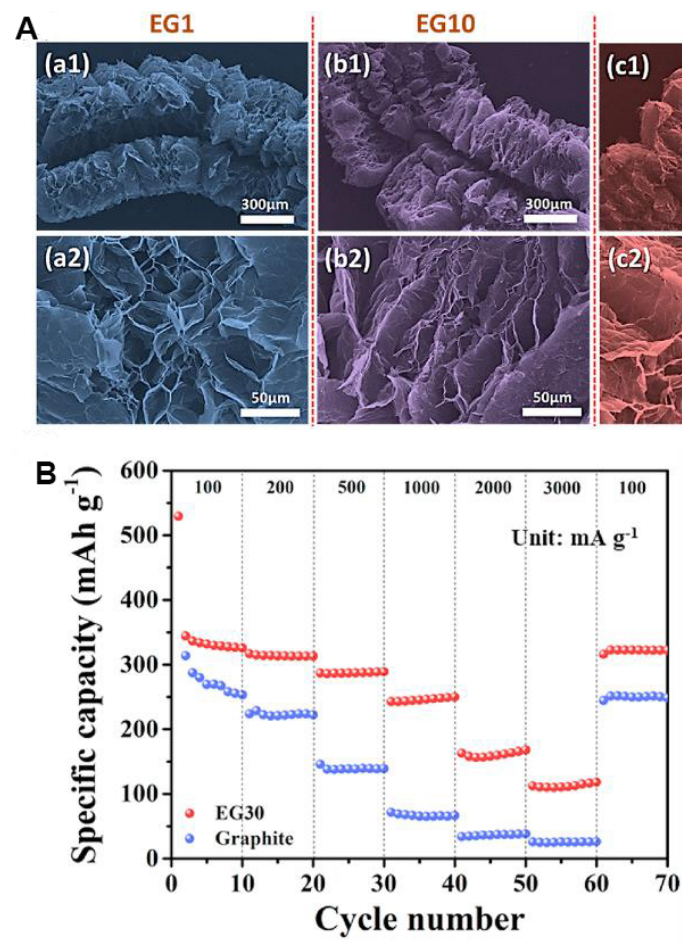

D

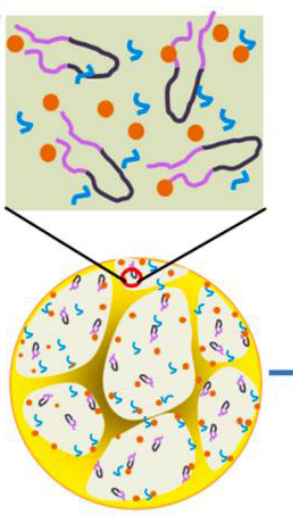

: PU foam

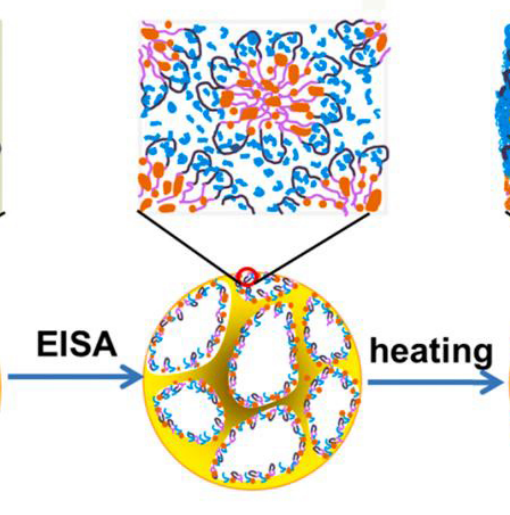

EtOH

$\bullet$ : resol
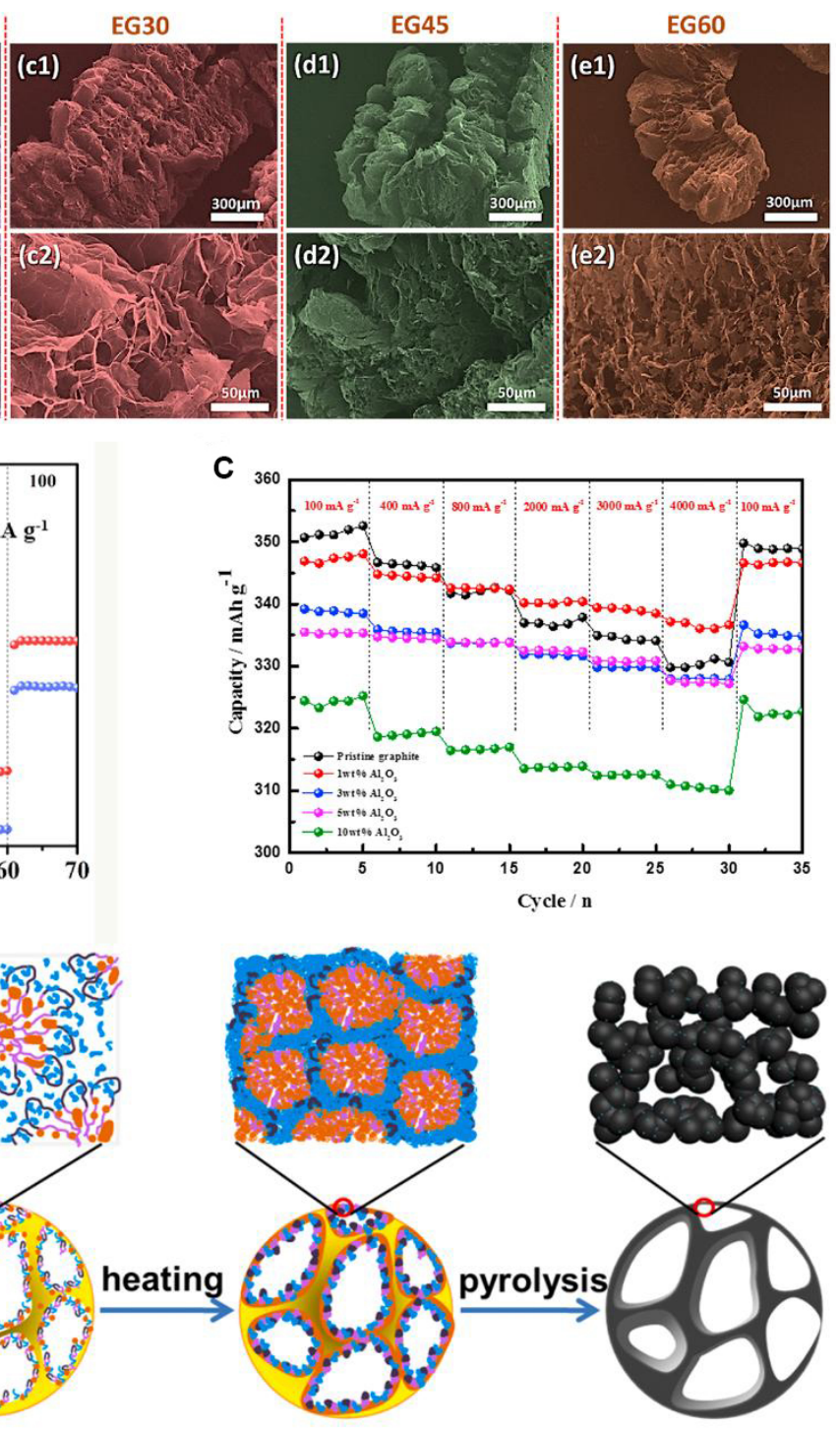

५: tricresyl phosphate

Figure 1. (A) SEM micrographs of EG samples at different magnifications. (B) Rate performance of EG30 and graphite ${ }^{[63]}$. (C) Rate capabilities of $\mathrm{Al}_{2} \mathrm{O}_{3} @$ graphite electrode ${ }^{[65]}$. (D) Schematic illustration of the synthesis of P-doped mesoporous carbons ${ }^{[73]}$. Reproduced from Refs. ${ }^{[63,65,73]}$ with permission from Elsevier. EG: Expandable graphite; EG30: the thermal exfoliation process of EG maintains 30 min; PU foam: polyurethane foam; EISA: evaporation induced self-assembly.

polyurethane foam was used as a sacrificial template [Figure 1D]. The obtained P-doped mesoporous carbon with a high P content (up to 1.90\%) consists of small collaterals and interconnected nanoparticles (10-20 nm), showing large adjustable mesopore dimensions (6.6-14.2 nm) and high surface areas (338-630 $\left.\mathrm{m}^{2} \mathrm{~g}^{-1}\right)$. When used as anodes for LIBs, these materials have excellent electrochemical storage performance. The P-doped mesoporous carbon shows a high reversible capacity of $500 \mathrm{~mA} \mathrm{~h} \mathrm{~g}^{-1}$ after 200 cycles at $0.5 \mathrm{C}$, outstanding rate performance and cycling stability after 100 cycles at $10 \mathrm{~A} \mathrm{~g}^{-1}$.

Furthermore, lithium titanium oxide $\left(\mathrm{Li}_{4} \mathrm{Ti}_{5} \mathrm{O}_{12}\right)$ is also a typical intercalation-type anode material and exhibits high safety and excellent cycling stability ${ }^{[79,80]}$. At room temperature, $\mathrm{Li}^{+}(1 / 6)$ and $\mathrm{Ti}^{4+}(5 / 6)$ ions are randomly dispersed at the $16 \mathrm{~d}$ site of the octahedron while the $\mathrm{O}$ atoms occupy all $32 \mathrm{e}$ sites. The structure 
can be represented by $\left[\mathrm{Li}_{3}\right]_{8 \mathrm{a}}\left[\mathrm{Ti}_{5} \mathrm{Li}\right]_{16 \mathrm{~d}}\left[\mathrm{O}_{12}\right]_{32 e^{21,82]}}$. The redox mechanism of $\mathrm{Li}_{4} \mathrm{Ti}_{5} \mathrm{O}_{12}$ consists of two stages. In the first stage, $\mathrm{Li}_{4} \mathrm{Ti}_{5} \mathrm{O}_{12}$ can be embedded with up to $3 \mathrm{moL} \mathrm{Li}$ at $\sim 1.5 \mathrm{~V}\left(v s\right.$. $\left.\mathrm{Li} / \mathrm{Li}^{+}\right)$to produce $\mathrm{Li}_{7} \mathrm{Ti}_{5} \mathrm{O}_{12}$. In the second stage, $\mathrm{Li}_{7} \mathrm{Ti}_{5} \mathrm{O}_{12}$ is inserted below $1 \mathrm{~V}\left(v s\right.$. $\left.\mathrm{Li} / \mathrm{Li}^{+}\right)$by 2 moL Li ${ }^{+}$to obtain $\mathrm{Li}_{9} \mathrm{Ti}_{5} \mathrm{O}_{12}$. In addition, the reaction equation can be expressed as ${ }^{[8,84]}$ :

$$
\left[\mathrm{Li}_{3}\right]_{8 \mathrm{a}}\left[\mathrm{Ti}_{5}^{4+} \mathrm{Li}\right]_{16 \mathrm{~d}}\left[\mathrm{O}_{12}\right]_{32 \mathrm{e}}+3 \mathrm{Li}^{+}+3 e^{-} \leftrightarrow\left[\mathrm{Li}_{6}\right]_{16 \mathrm{c}}\left[\mathrm{Ti}_{3}^{3+} \mathrm{Ti}_{2}^{4+} \mathrm{Li}\right]_{16 \mathrm{~d}}\left[\mathrm{O}_{12}\right]_{32 \mathrm{e}}
$$

$$
\left[\mathrm{Li}_{6}\right]_{16 \mathrm{c}}\left[\mathrm{Ti}_{3}^{3+} \mathrm{Ti}_{2}^{4+} \mathrm{Li}\right]_{16 \mathrm{~d}}\left[\mathrm{O}_{12}\right]_{32 \mathrm{e}}+2 \mathrm{Li}^{+}+2 e^{-} \leftrightarrow\left[\mathrm{Li}_{2}\right]_{8 \mathrm{a}}\left[\mathrm{Li}_{6}\right]_{16 \mathrm{c}}\left[\mathrm{Ti}_{5}^{3+} \mathrm{Li}_{16 \mathrm{~d}}\left[\mathrm{O}_{12}\right]_{32 \mathrm{e}}\right.
$$

Surprisingly, the structure of $\mathrm{Li}_{4} \mathrm{Ti}_{5} \mathrm{O}_{12}$ changes only slightly during charging and discharging. In addition, Figure $2 \mathrm{~A}$ shows the delithiation/lithiation process of $\mathrm{Li}_{4} \mathrm{Ti}_{5} \mathrm{O}_{12}$ at $3,1-3$ and 0.01-1 $\mathrm{V}$, respectively ${ }^{[83]}$. However, due to the low conductivity of $\mathrm{Li}_{4} \mathrm{Ti}_{5} \mathrm{O}_{12}\left(10^{-13} \mathrm{~S} \mathrm{~cm}^{-1}\right)^{[5]}$, it is difficult to transfer electrons from the $\mathrm{Li}_{4} \mathrm{Ti}_{5} \mathrm{O}_{12}$ electrode to the external circuit, resulting in high electrode polarization during the continuous cycling process, especially at high current density, which seriously limits its practical application. Researchers have utilized many strategies to enhance the electronic conductivity of $\mathrm{Li}_{4} \mathrm{Ti}_{5} \mathrm{O}_{12}$ anodes and enhance their electrochemical performance. Surface modification and doping can improve the ion diffusion and conductivity, which can improve the high rate performance of the material ${ }^{[85-88]}$.

Ion doping usually reduces the theoretical capacity of spinel $\mathrm{Li}_{4} \mathrm{Ti}_{5} \mathrm{O}_{12}$ due to the decrease in active $\mathrm{Ti}$ or $\mathrm{Li}$. Hence, the development of new $\mathrm{Li}_{4} \mathrm{Ti}_{5} \mathrm{O}_{12}$-based materials is imperative in the field of high-power LIBs. In addition, considering the cost of $\mathrm{Li}$, it is vital to exploit low $\mathrm{Li}$ intercalation-type Ti-based anode materials. Lately, our group constructed a new $\mathrm{Cr}$,Ti-based complex, $\mathrm{Li}_{5} \mathrm{Cr}_{7} \mathrm{Ti}_{6} \mathrm{O}_{25}$, with a low content of Li. According to the one-electron transfer of $\mathrm{Ti}^{4+/ 3+}$ and $\mathrm{Cr}^{2+/ 3+}$ ions, the theoretical capacity of $\mathrm{Li}_{5} \mathrm{Cr}_{7} \mathrm{Ti}_{6} \mathrm{O}_{25}$ is $\sim 320 \mathrm{mAh} \cdot \mathrm{g}^{-1}$ when cycled between 3 and $0 \mathrm{~V}$. According to the one-electron transfer of $\mathrm{Ti}^{4+/ 3+}$, the theoretical capacity of $\mathrm{Li}_{5} \mathrm{Cr}_{7} \mathrm{Ti}_{6} \mathrm{O}_{25}$ is $\sim 147 \mathrm{mAh} \cdot \mathrm{g}^{-1}$ when cycled between 3 and $1 \mathrm{~V}$. Therefore, $\mathrm{Li}_{5} \mathrm{Cr}_{7} \mathrm{Ti}_{6} \mathrm{O}_{25}$ as a promising anode material has also received significant attention ${ }^{[89]}$. Mei et al. ${ }^{[90]}$ prepared $\mathrm{Li}_{5} \mathrm{Cr}_{7} \mathrm{Ti}_{6} \mathrm{O}_{25} @ \mathrm{CeO}_{2}$ composite electrode materials by a simple high-temperature solid phase method and studied the effects of different coating amounts of $\mathrm{CeO}_{2}$ on the electrochemical properties of electrode materials. The results show that $\mathrm{Li}_{5}$ $\mathrm{Cr}_{7} \mathrm{Ti}_{6} \mathrm{O}_{25}$ has the best electrochemical performance when the coating amount of $\mathrm{CeO}_{2}$ is $3 \mathrm{wt}$.\%. In particular, the reversible capacity is $101 \mathrm{mAh} \cdot \mathrm{g}^{-1}$ when cycled between 3 and $1 \mathrm{~V}$ after 100 cycles at $5 \mathrm{C}$. According to the TEM image, the existence of a coating layer can be clearly seen, indicating that there is an interface between $\mathrm{Li}_{5} \mathrm{Cr}_{7} \mathrm{Ti}_{6} \mathrm{O}_{25}$ and $\mathrm{CeO}_{2}$. Figure $2 \mathrm{~B}$ shows the interface model. According to first-principles calculations, the crystal plane mismatch of the two materials is only $8 \%$, which theoretically explains how the $\mathrm{CeO}_{2}$ coating can effectively enhance the cycling performance of the materials.

Figure $3 \mathrm{~A}$ shows a schematic of $\mathrm{Li}_{4} \mathrm{Ti}_{5} \mathrm{O}_{12}$ with various $0 \mathrm{D}, 1 \mathrm{D}, 2 \mathrm{D}$ and $3 \mathrm{D}$ nano/microstructures ${ }^{[80]}$. The morphology control of $\mathrm{Li}_{4} \mathrm{Ti}_{5} \mathrm{O}_{12}$ can be utilized to reduce the diffusion distance of $\mathrm{Li}^{+[1,92]}$. In addition, the nanostructures increase the surface area that can be used to reduce interfacial charge transfer, thus substantially improving the electrochemical activity. Therefore, nanostructured electrodes generally have higher power densities than coarse powder electrodes. The addition of micrometer particles to the holes is another effective method for increasing the rate properties of electrode materials. Micron-sized porous electrodes have the advantage of being easy to assemble and are used for short diffusion pathways of lithium ions. The porous structure can increase the surface area of the electrode material, thus exposing more active sites for lithium-ion insertion into the electrode material, while the nanometer thick wall shortens the diffusion distance of lithium. The nanostructures help to reduce electrode polarization. Microparticles with 

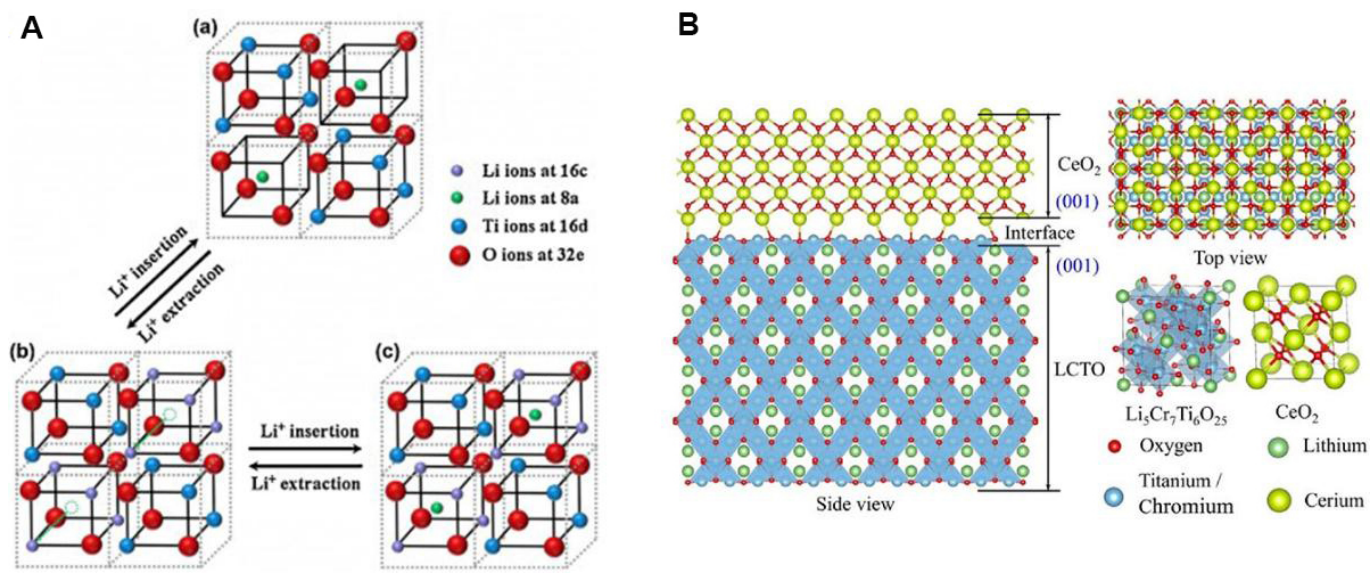

Figure 2. (A) Schematic illustration of the $\mathrm{Li}^{+}$interaction and deintercalation from the spinel $\mathrm{Li}_{4} \mathrm{Ti}_{5} \mathrm{O}_{12}$ structure at (a) 3 , (b) $1-3$ and (c) 0.01-1 $\mathrm{V}^{[83]}$. Reproduced from Ref. ${ }^{[83]}$ with permission from Elsevier. (B) Interface model between $\mathrm{Li}_{5} \mathrm{Cr}_{7} \mathrm{Ti}_{6} \mathrm{O}_{25}$ and $\mathrm{CeO}_{2}{ }^{[90]}$. Reproduced from Ref. ${ }^{[90]}$ with permission from the American Chemical Society.

a 3D structure can also ensure contact between the particles, thus increasing the stability of the electrode and inhibiting the capacity loss. The three common preparation pathways of porous $\mathrm{Li}_{4} \mathrm{Ti}_{5} \mathrm{O}_{12}$ are summarized in Figure 3B. The first route uses a template or hole front to fabricate pores in the sample. The pore size and porosity can be easily adjusted by using various templates or pore formers. The second method is combustion synthesis. The formation of pores is mainly through the diffusion of gas in the reaction process. The process of this method is relatively simple but the controllability is poor. The third method is self-assembly synthesis. Pores arise from voids produced from a particular structure and sites left by the removal of some organic groups.

In recent years, a series of research results on $\mathrm{Nb}$-based oxide materials as anode materials have shown significant advantages in the performance of batteries ${ }^{[93,94]}$. Nb-based oxides have a high potential window (> $1 \mathrm{~V} v$ s. $\left.\mathrm{Li} / \mathrm{Li}^{+}\right)$, similar to $\mathrm{Li}_{4} \mathrm{Ti}_{5} \mathrm{O}_{12}$, which effectively prevents the formation of lithium dendrites and SEI films. The high specific capacity of $\mathrm{Nb}$-based oxides is due to two $\mathrm{Li}^{+}$insertion and extraction during the charge-discharge process, corresponding to $\mathrm{Nb}^{5+} / \mathrm{Nb}^{4+}$ and $\mathrm{Nb}^{4+} / \mathrm{Nb}^{3+}$, respectively ${ }^{[95-97]}$. Nb-based oxides are a large family, mainly including the following two types: the $\mathrm{Nb}$-O type represented by $\mathrm{Nb}_{2} \mathrm{O}_{5}$ and the $\mathrm{M}$ $\mathrm{Nb}-\mathrm{O}$ type represented by $\mathrm{TiNb}_{x} \mathrm{O}_{2+2.5 x}$. $\mathrm{Nb}-\mathrm{O}$ compounds include $\mathrm{NbO}(2+), \mathrm{Nb}_{2} \mathrm{O}_{3}(3+), \mathrm{NbO}_{2}(4+)$ and $\mathrm{Nb}_{2}$ $\mathrm{O}_{5}(5+) . \mathrm{Nb}_{2} \mathrm{O}_{5}$ is the most common and stable, as well as one of the most studied ${ }^{[98]}$. As shown in Figure 4, $\mathrm{Nb}_{2} \mathrm{O}_{5}$ mainly includes pseudo-hexagonal $\left(\mathrm{TT}-\mathrm{Nb}_{2} \mathrm{O}_{5}\right.$ ), orthogonal $\left(\mathrm{T}-\mathrm{Nb}_{2} \mathrm{O}_{5}\right.$ ) and monoclinic crystal

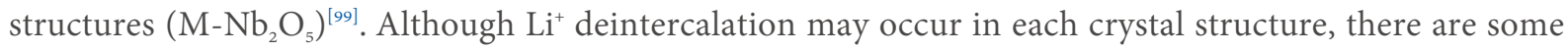
differences in their electrochemical behavior and performance. Notably, orthogonal $\mathrm{T}-\mathrm{Nb}_{2} \mathrm{O}_{5}$ has attracted increasing attention due to its pseudocapacitivity ${ }^{[100]}$. In addition, its (001) lattice spacing (3.90 $\AA$ ) is about twice the diameter of $\mathrm{Li}^{+}(1.52 \AA)$. Such large lattice spacing accelerates the diffusion of $\mathrm{Li}^{+}$. In addition, the volume change during the insertion/extraction process of $\mathrm{Li}^{+}$is very small, ensuring a long service life ${ }^{[101]}$.

Compared with $\mathrm{Nb}_{2} \mathrm{O}_{5}, \mathrm{M}-\mathrm{Nb}-\mathrm{O}$ materials show higher specific capacity. For example, the Ti-Nb-O group has three redox electric pairs of $\mathrm{Ti}^{4+} / \mathrm{Ti}^{3+}, \mathrm{Nb}^{5+} / \mathrm{Nb}^{4+}$ and $\mathrm{Nb}^{4+} / \mathrm{Nb}^{3+}$, which have a large theoretical capacity ${ }^{[102]}$. In addition, most of the Ti-Nb-O groups can be represented by the chemical formula $\mathrm{TiNb}_{x} \mathrm{O}_{2+2.5 x}$, such as $\mathrm{TiNb}_{2} \mathrm{O}_{7}(x=2), \mathrm{Ti}_{2} \mathrm{Nb}_{10} \mathrm{O}_{29}(x=5), \mathrm{TiNb}_{6} \mathrm{O}_{17}(x=6)$ and $\mathrm{TiNb}_{24} \mathrm{O}_{62}(x=24)^{[102,103]}$. The theoretical capacity $\left(\mathrm{mAh} \cdot \mathrm{g}^{-1}\right)$ is calculated as follows ${ }^{[103]}$ : 

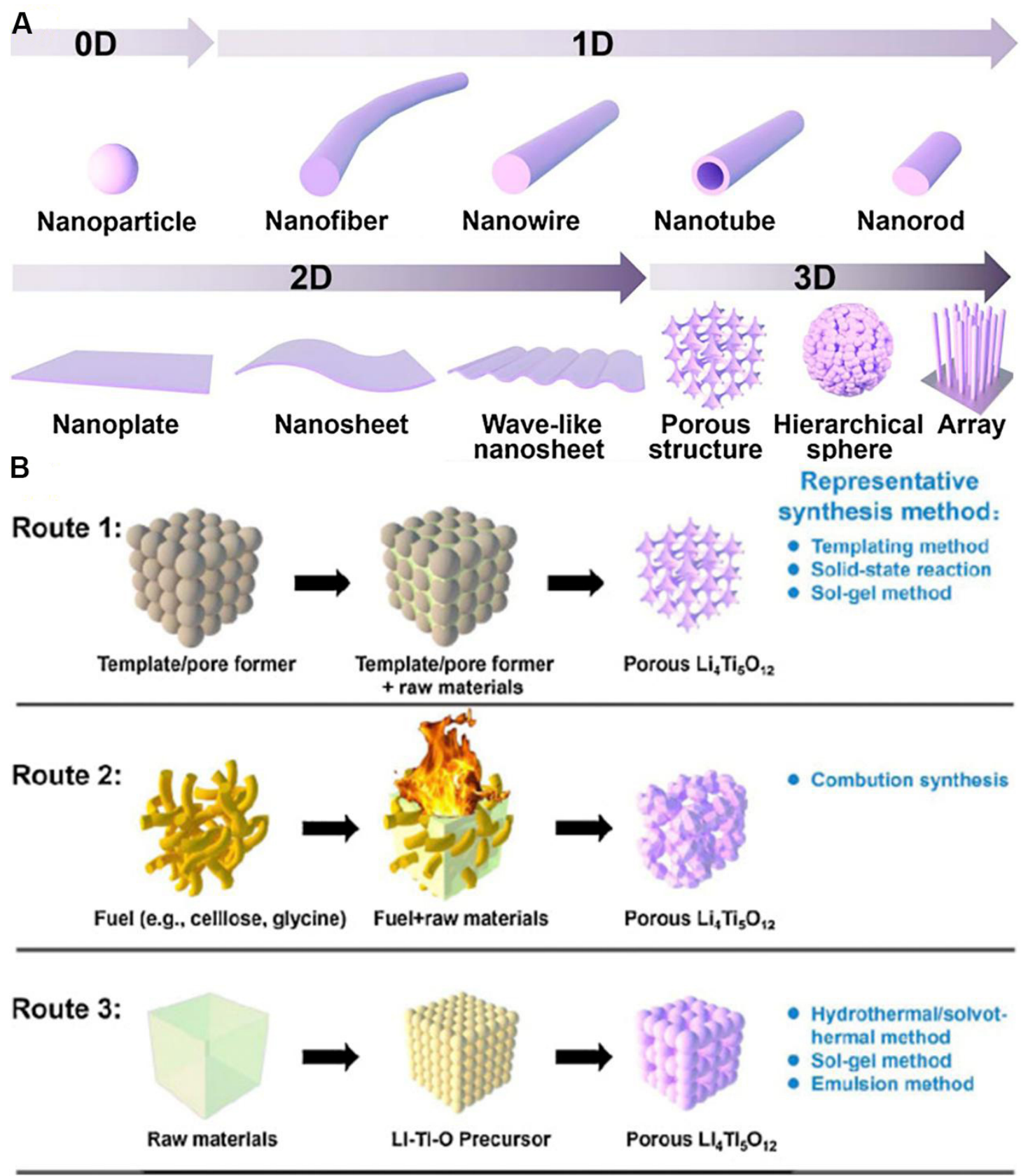

Figure 3. (A) Schematics of reported $\mathrm{Li}_{4} \mathrm{Ti}_{5} \mathrm{O}_{12}$ nano/microstructures (O-3D). (B) Typical methods for the preparation of porous $\mathrm{Li}_{4} \mathrm{Ti}_{5} \mathrm{O}_{12}$ and the corresponding representative synthesis method ${ }^{[80]}$. Reproduced from Ref. ${ }^{[80]}$ with permission from Elsevier.

$$
C=403-5441 /(133 x+80)
$$

Thus, the theoretical capacities of $\mathrm{TiNb}_{2} \mathrm{O}_{7}, \mathrm{Ti}_{2} \mathrm{Nb}_{10} \mathrm{O}_{29}, \mathrm{TiNb}_{6} \mathrm{O}_{17}$ and $\mathrm{TiNb}_{24} \mathrm{O}_{62}$ are 388, 396, 397 and 401 $\mathrm{mAh} \cdot \mathrm{g}^{-1}$, respectively, which are about 1.2 times the theoretical capacity of $\mathrm{Li}_{4} \operatorname{Ti}_{5} \mathrm{O}_{12}(0-3 \mathrm{~V})$ and even higher than that of graphite. However, they all have the inherent problem of poor electrical conductivity and their theoretical capacity is relatively low relative to alloying and conversion-type anode materials. So far, researchers have conducted a series of studies on these existing problems and made remarkable 

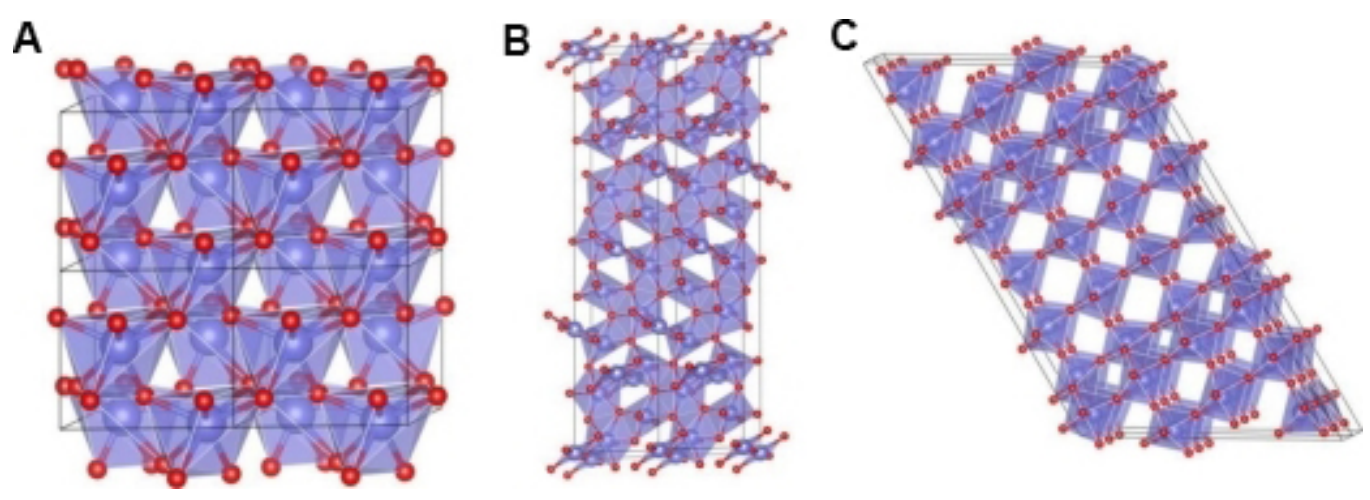

Figure 4. Crystal structures of $(\mathrm{A}) \mathrm{TT}-\mathrm{Nb}_{2} \mathrm{O}_{5} ;(\mathrm{B}) \mathrm{T}-\mathrm{Nb}_{2} \mathrm{O}_{5}$; and (C) $\mathrm{M}-\mathrm{Nb}_{2} \mathrm{O}_{5}{ }^{[99]}$. Reproduced from Ref. ${ }^{[99]}$ with permission from Elsevier.

achievements. There are many strategies for improving $\mathrm{M}-\mathrm{Nb}-\mathrm{O}$ materials, mainly involving structural engineering $^{[104,105]}$, doping ${ }^{[106,107]}$ and conductive phase modification ${ }^{[108,109]}$. Conductive phase modification is considered to be a direct and effective method for improving their electrical conductivity.

Carbonaceous materials are the most common modified conductive phase because of their variety, low cost and good electrical conductivity. Liu et al. ${ }^{[10]}$ synthesized $\mathrm{Ti}_{2} \mathrm{Nb}_{10} \mathrm{O}_{29} / \mathrm{C}$ composites by a simple hightemperature solid phase method. As shown in Figures 5A and B, the size and morphology of the two samples are almost the same and the average particle size is $\sim 1 \mu \mathrm{m}$. Compared with pure $\mathrm{Ti}_{2} \mathrm{Nb}_{10} \mathrm{O}_{29}$, $\mathrm{Ti}_{2} \mathrm{Nb}_{10} \mathrm{O}_{29} / \mathrm{C}$ composites have relatively high uniformity and dispersion. The discharge capacities of the composite samples at 1, 5 and $10 \mathrm{C}$ were $295.5,224.8$ and $204 \mathrm{mAh} \cdot \mathrm{g}^{-1}$, respectively. The discharge capacities were 255.7, 214.3 and $194 \mathrm{mAh} \cdot \mathrm{g}^{-1}$ after 100 cycles, respectively, showing the good stability of the materials. Moreover, as shown in Figure $5 \mathrm{C}$, the capacities reach 180.3 and $145 \mathrm{mAh} \cdot \mathrm{g}^{-1}$ when the current density increases from 20 to $30 \mathrm{C}$. This significant enhancement of the magnification performance is attributed to the improved electronic conductivity resulting from the introduction of amorphous carbon. Ashish et al. ${ }^{[11]}$ prepared $\mathrm{TiNb}_{2} \mathrm{O}_{7} /$ Graphene (TNO-TG) composite nanomaterials according to a common solvothermal method, where the $\mathrm{TiNb}_{2} \mathrm{O}_{7}$ nanoparticles were anchored on the graphene nanosheets [Figures 5D and E]. The TNO-TG anode enhanced the electrical conductivity and showed an extremely high rate performance. The retention rate was more than $80 \%$ at $16 \mathrm{C}$ and the discharge capacity was $230 \mathrm{mAh} \cdot \mathrm{g}^{-1}$.

In addition to the above electrode materials, $\mathrm{Li}_{3} \mathrm{VO}_{4}$ is another competitive intercalation-type anode material because of its suitable voltage platform $(\sim 1.5 \mathrm{~V})$ and high theoretical capacity $\left(394 \mathrm{mAh} \cdot \mathrm{g}^{-1}\right)$. Shi et al. ${ }^{[112]}$ synthesized a $\mathrm{Li}_{3} \mathrm{VO}_{4} /$ graphene composite by a one-step in situ hydrothermal method. As shown in Figure $5 \mathrm{~F}-\mathrm{H}$, the $\mathrm{Li}_{3} \mathrm{VO}_{4}$ /graphene composite exhibits a unique hollow structure with microbox morphology, a $40 \mathrm{~nm}$ wall thickness and is wrapped with porous graphene nanosheets. This hollow structure not only relaxes the stress/strain of Li-ion insertion/extraction, but also increases the surface area of the material. This can offer extra space for lithium storage and reduce the effective diffusion path of lithium ions. Even at $20 \mathrm{C}\left(1 \mathrm{C}=400 \mathrm{~mA} \cdot \mathrm{g}^{-1}\right)$, the $\mathrm{Li}_{3} \mathrm{VO}_{4} /$ graphene composite shows a reversible capacity of $223 \mathrm{mAh} \cdot \mathrm{g}^{-1}$. After 500 cycles at $10 \mathrm{C}$, there is no significant capacity fading. However, the formation mechanism of hollow structures has not been discussed in detail. Subsequently, Shi et al. ${ }^{[113]}$ synthesized hollow $\mathrm{Li}_{3} \mathrm{VO}_{4}$ microboxes by a fast one-step in situ hydrothermal method and comprehensively studied and discussed their formation mechanism caused by the evacuation process from the interior and the precipitation on the surface. The resulting materials revealed a unique morphology and excellent electrochemical properties. Therefore, $\mathrm{Li}_{3} \mathrm{VO}_{4}$ is a promising anode candidate for the development of highperformance, low-cost and advanced LIBs. 

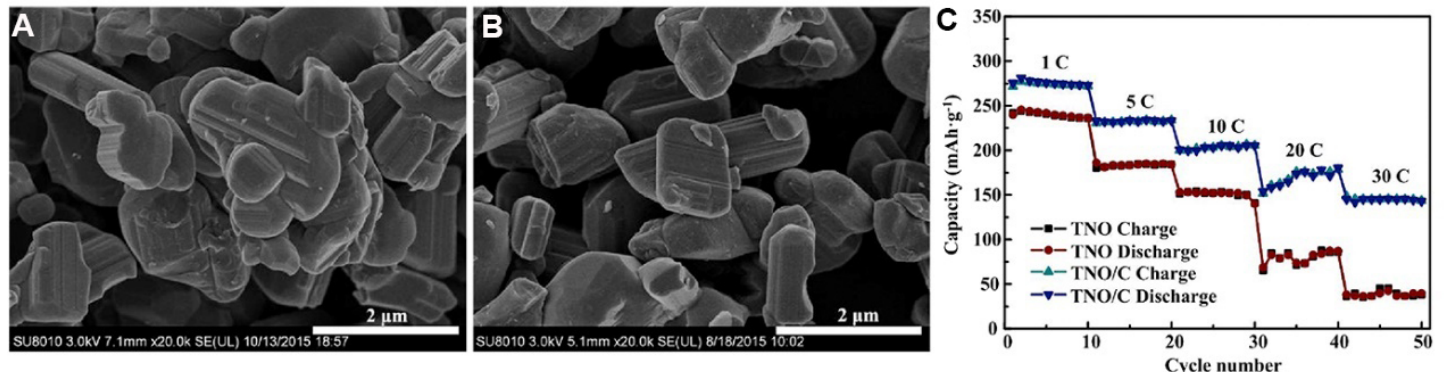

D
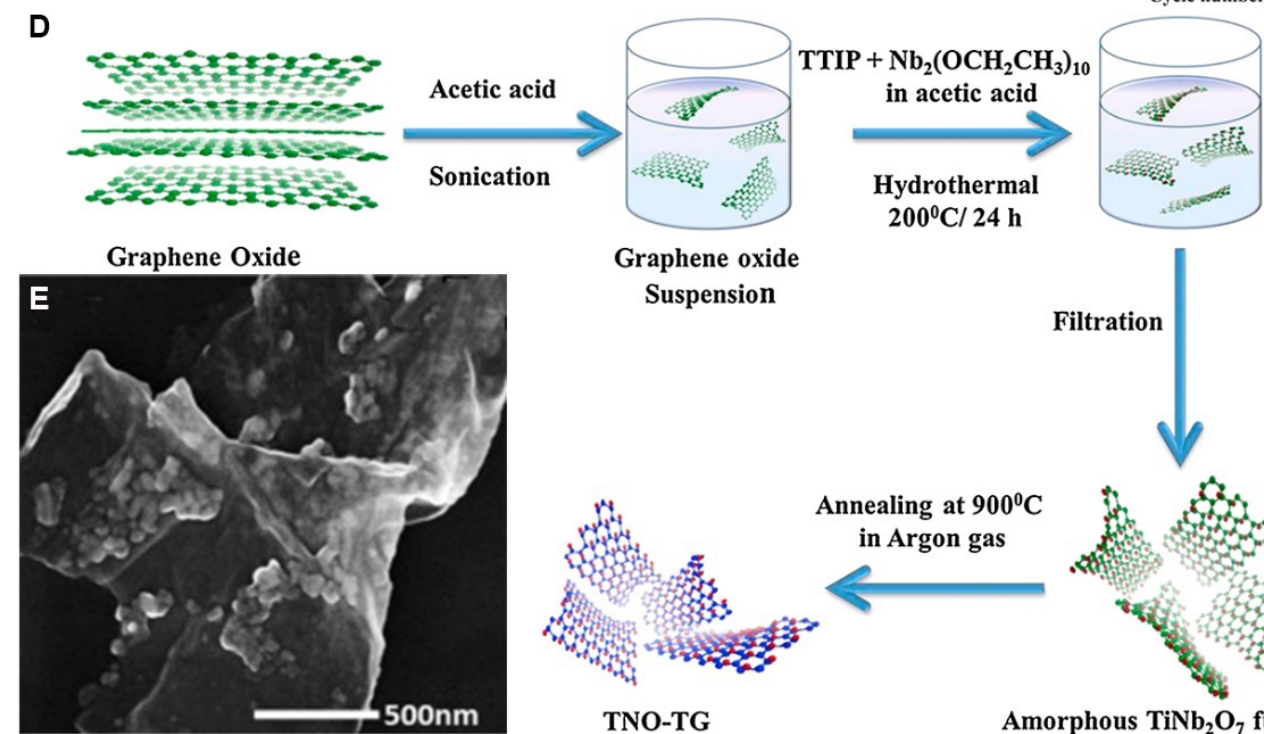

Graphene oxide $200^{\circ} \mathrm{C} / 24 \mathrm{~h}$

Suspension
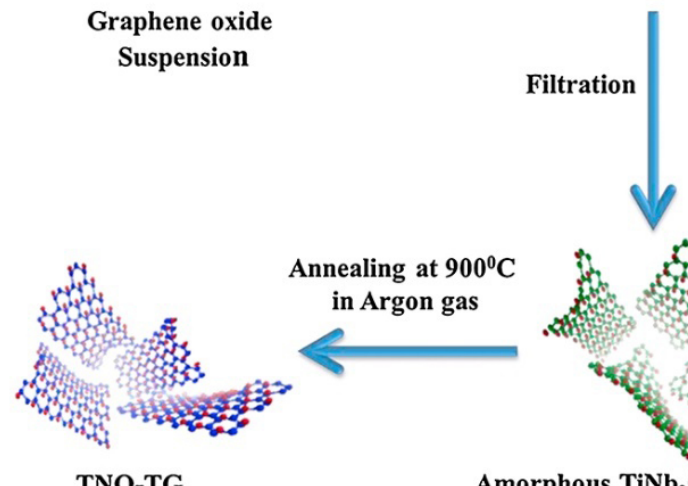

Annealing at $900^{\circ} \mathrm{C}$ in Argon gas
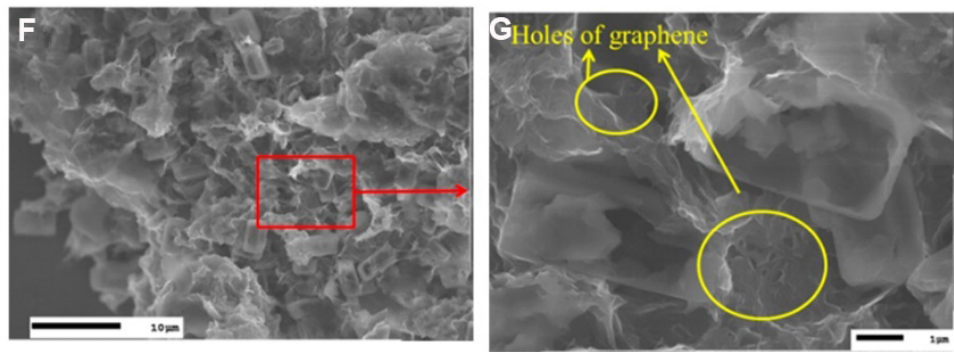

Amorphous $\mathrm{TiNb}_{2} \mathrm{O}_{7}$ functionalised

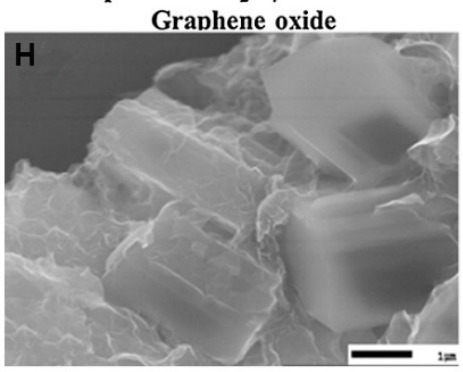

Figure 5. $\mathrm{SEM}$ images of (A) $\mathrm{Ti}_{2} \mathrm{Nb}_{10} \mathrm{O}_{29}$ and (B) $\mathrm{Ti}_{2} \mathrm{Nb}_{10} \mathrm{O}_{29} / \mathrm{C}$ composites. (C) Rate performance of $\mathrm{Ti}_{2} \mathrm{Nb}_{10} \mathrm{O}_{29}$ and $\mathrm{Ti}_{2} \mathrm{Nb}_{10} \mathrm{O}_{29} / \mathrm{C}^{[110]}$. (D) Schematic illustration and (E) TEM image of $\mathrm{TiNb}_{2} \mathrm{O}_{7} /$ graphene electrodes $^{[111]}$. (F-H) FESEM micrographs of $\mathrm{LVO}^{2} \mathrm{G}^{[112]}$. Reproduced from Refs. ${ }^{[110,111]}$ with permission from Elsevier. Reproduced from Ref. ${ }^{[112]}$ with permission from the American Chemical Society.

\section{CONVERSION-TYPE ANODE MATERIALS}

Conversion-type anode materials (CTAMs) mainly refer to transition metal oxides ${ }^{[114-16]}$, sulfides ${ }^{[26]}$, phosphides $^{[117]}$ and nitrogen compounds ${ }^{[118]}(\mathrm{M}=\mathrm{Co}, \mathrm{Ni}, \mathrm{Fe}$ or $\mathrm{Mn})$. The transformation reaction of metal oxides and sulfides with $\mathrm{Li}^{+}$is as follows ${ }^{[119]}$ :

$$
\begin{aligned}
& \mathrm{M}_{x} \mathrm{O}_{y}+2 y \mathrm{Li}^{+}+2 y e^{-} \leftrightarrow x \mathrm{M}+y \mathrm{Li}_{2} \mathrm{O} \\
& \mathrm{M}_{x} \mathrm{~S}_{y}+2 y \mathrm{Li}^{+}+2 y e \leftrightarrow x \mathrm{M}+y \mathrm{Li}_{2} \mathrm{~S}
\end{aligned}
$$


Because there is no position for $\mathrm{Li}^{+}$insertion and extraction in the spatial structure of CTAMs, it is generally believed that the reaction with $\mathrm{Li}$ at room temperature is irreversible. CTAMs possess some advantages, such as composition diversity and high theoretical capacity. A schematic of the lithium storage mechanism of typical CTAMs is depicted in Figure $6 \mathrm{~A}^{[120]}$. Wang et al. ${ }^{[121]}$ obtained a $\mathrm{NiO}$ nanooctahedron with a unique structure by pyrolysis of hexagonal nickel nanoplate microspheres. Such a structure not only offers a large surface area for rapid diffusion of $\mathrm{Li}^{+}$between the anode and the electrolyte, but the exposed active surface can also effectively improve charge transport motion mechanics and lithium-ion diffusion. The reversible specific capacity of $\mathrm{NiO}$ can reach $792 \mathrm{mAh} \cdot \mathrm{g}^{-1}$ after 200 cycles at $0.2 \mathrm{C}$, which fully indicates that $\mathrm{NiO}$ has outstanding cycle performance as an anode material for LIBs. Choi et al. ${ }^{[122]}$ prepared $\mathrm{Fe}_{3} \mathrm{O}_{4}$-decorated hollow graphene spherical composites according to spray pyrolysis. Figure $6 \mathrm{~B}$ exhibits a detailed schematic of the formation process of hollow $\mathrm{Fe}_{3} \mathrm{O}_{4}$ /graphene spheres and the electrochemical reaction mechanism. The structure integrity of the $\mathrm{Fe}_{3} \mathrm{O}_{4}$-decorated hollow graphene spheres composites can be well maintained during the deintercalation of lithium, indicating that the hollow $\mathrm{Fe}_{3} \mathrm{O}_{4} /$ graphene spheres have good structural stability and the cycling performance of the hollow $\mathrm{Fe}_{3} \mathrm{O}_{4}$ /graphene spheres is improved after long cycling at high current density. $\mathrm{Fe}_{3} \mathrm{O}_{4}$ was still uniformly dispersed on the graphene spheres after a long period of cycling without aggregation.

Luo et al. ${ }^{[114]}$ used SEM, selected electron diffraction and high-resolution transmission electron microscopy to study the transformation process of $\mathrm{Co}_{3} \mathrm{O}_{4}$ nanocrystals with a particle size of $\sim 5 \mathrm{~nm}$ [Figure $7 \mathrm{~A}-\mathrm{C}$ ] and the reaction mechanism of $\mathrm{Co}_{3} \mathrm{O}_{4}$ as a $\mathrm{LIB}$ anode. As shown in Figure 7D, lithium ions enter into the phase of $\mathrm{Co}_{3} \mathrm{O}_{4}$ (i.e., $\mathrm{Li}_{\mathrm{x}} \mathrm{Co}_{3} \mathrm{O}_{4}$ ) in the process of lithiation, which is composed of nano-Co-Li-O clusters and is regarded as the intermediate product of the transformation reaction. In the final stage of lithiation, the $\mathrm{CO}_{3} \mathrm{O}_{4}$ nanotube is completely transformed into a mixture of $\mathrm{Li}_{2} \mathrm{O}$ substrate and Co elemental clusters growing in it, with significant volume expansion and lattice collapse. This in situ observation is a demonstration of the real behavior of the material during the charging and discharging process, which can deepen our understanding of the mechanism of CTAM reaction and guide us to improve the material performance.

Cho et al. ${ }^{[15]}$ prepared a $1 \mathrm{D}$ nanorod-like $\mathrm{Fe}_{2} \mathrm{O}_{3} / \mathrm{C}$ electrode material using a simple and general electrospinning method by the Kirkendall effect and studied the formation mechanism of the nanobubble structure in detail by tracking and observing each step of the nanobubble formation process [Figure 8A]. According to SEM [Figure $8 \mathrm{~B}$ ] and TEM [Figure $8 \mathrm{C}$ ] images, the nanofiber consists of hollow $\mathrm{Fe}_{2} \mathrm{O}_{3}$ spheres evenly dispersed in an amorphous carbon matrix, which has the advantages of a large specific surface area, short diffusion path of lithium ions and direct and efficient electron transport channels. This enables the material to interact with $\mathrm{Li}^{+}$more effectively, thus giving it with excellent rate capability. In addition, its special bubble-like structure also allows the $\mathrm{Fe}_{2} \mathrm{O}_{3}$ bubble void and surrounding carbon atoms to effectively regulate the mechanical stress generated in the process of charging and discharging. Hence, the cycle life of the material is improved. The $\mathrm{Fe}_{2} \mathrm{O}_{3} / \mathrm{C}$ nanorods exhibited excellent cycling performance when used as an anode electrode of LIBs. During the first thirty cycles, the specific capacity of $\mathrm{Fe}_{2} \mathrm{O}_{3} / \mathrm{C}$ nanorods has a slight decrease, but almost no decrease from the 31st to the 300th cycles, reaching a maximum of $824 \mathrm{mAh} \cdot \mathrm{g}^{-1}$ at 1 $\mathrm{A} \mathrm{g}^{-1}$. When the measured current density gradually rises from 0.5 to $5 \mathrm{~A} \mathrm{~g}^{-1}$ and then backs to $0.5 \mathrm{~A} \mathrm{~g}^{-1}$, the capacity of the material only slightly decreases. When the current density reaches the maximum, the specific capacity remains at $491 \mathrm{mAh} \cdot \mathrm{g}^{-1}$, which fully demonstrates the excellent structure.

However, this transformation mechanism was first intercalated to form highly electroactive $\mathrm{M}$ nanoparticles and $\mathrm{Li}_{n} \mathrm{X}$ matrix surrounded by a SEI film. Due to a large amount of structural rearrangement after lithiation, the voltage lag of CATMs during discharge and charge leads to low energy density and internal 


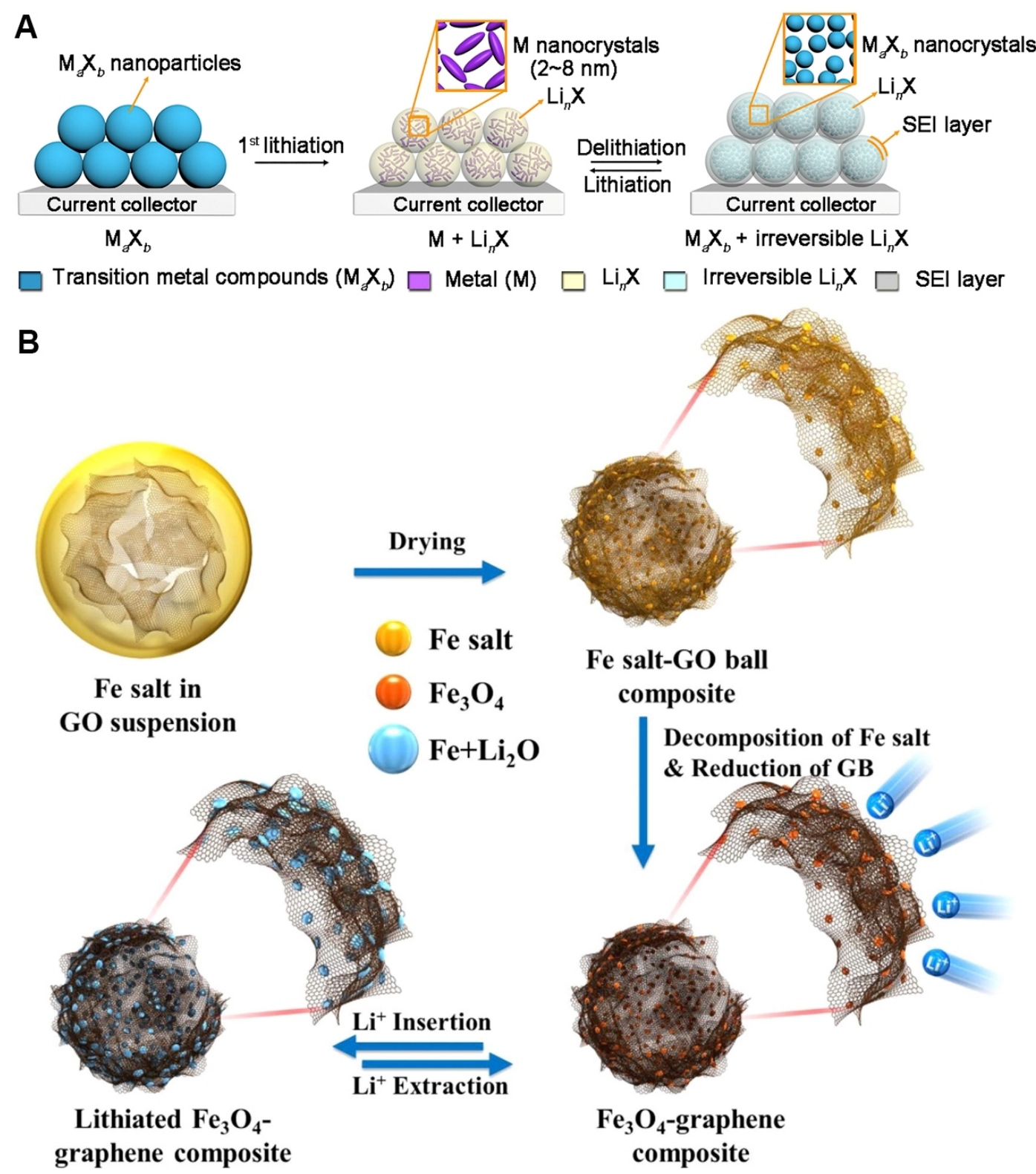

Figure 6. (A) Schematic of chemical transformation of transition metal compounds during charging and discharging ${ }^{[120]}$. (B) Schematic of the formation of hollow $\mathrm{Fe}_{3} \mathrm{O}_{4} /$ graphene balls and the electrochemical reaction mechanism ${ }^{[122]}$. Reproduced from Refs. ${ }^{[120,122]}$ with permission from Elsevier.

thermal evolution. The voltage lag is closely related to the properties of anions, so the hysteresis is most obvious for fluorides, followed by oxides, sulfides, nitrides and phosphides ${ }^{[120]}$. In addition, due to its low inherent conductivity and the powder pulverization problem in the repeated cycling process, the rate capacity is poor and the capacity decay is fast ${ }^{[123]}$. Therefore, significant progress must be made before CATMs become practical electrode materials.

\section{ALLOYING-TYPE ANODE MATERIALS}

Alloyed anode materials primarily belong to the IVA and VA groups, which include $\mathrm{Si}, \mathrm{Ge}, \mathrm{Sn}, \mathrm{Pb}, \mathrm{P}, \mathrm{As}, \mathrm{Sb}$ and $\mathrm{Bi}$. The lithium storage mechanism is an alloying reaction with lithium to form a $\mathrm{Li}_{w} \mathrm{M}$ alloy ${ }^{[124]}$. The 

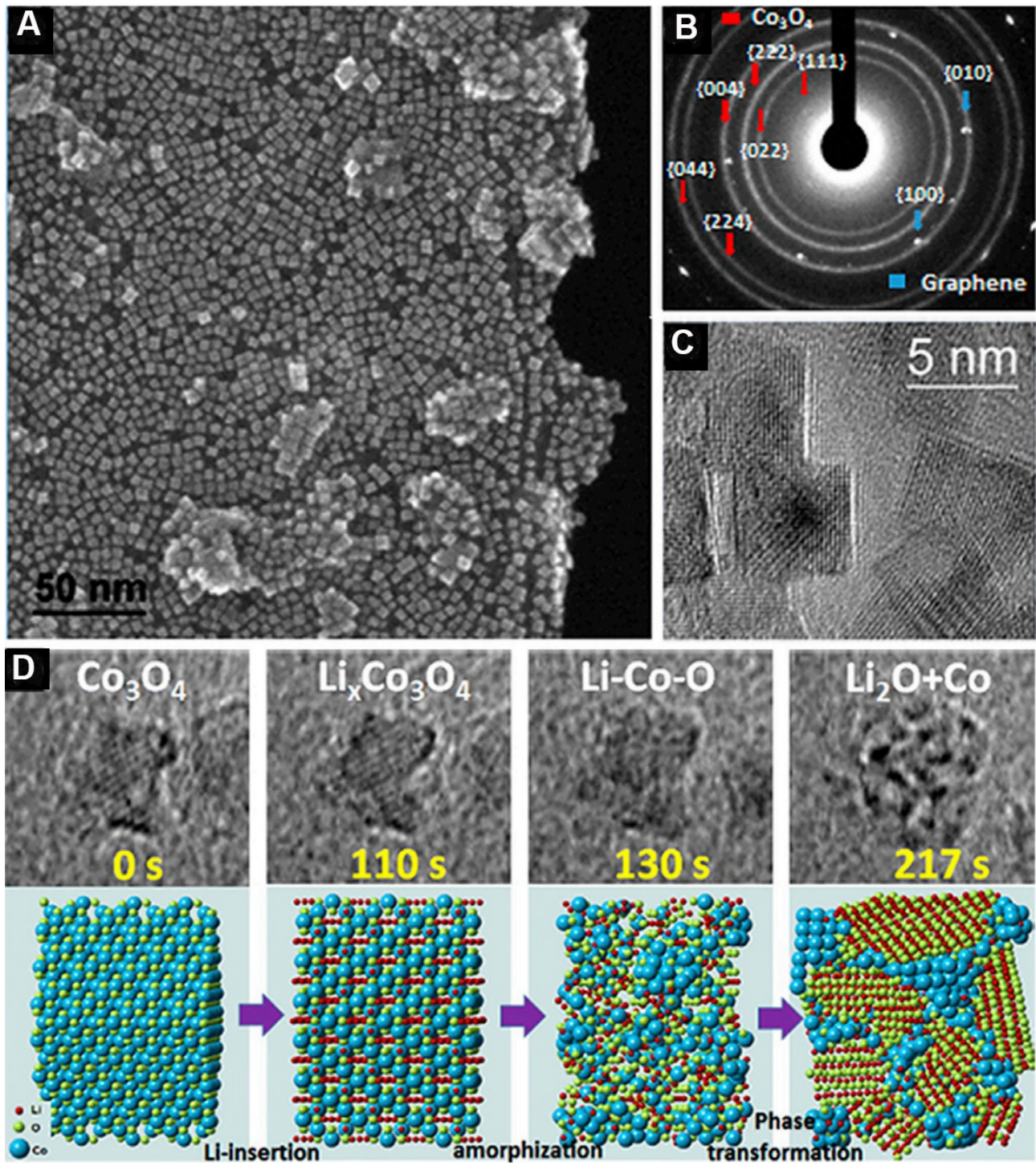

Figure 7. (A) SEM image; (B) SAED pattern; and (C) HRTEM image of $\mathrm{Co}_{3} \mathrm{O}_{4}$ nanocubes. (D) In situ HRTEM pattern and schematic atomistic models of the lithiation process of a single $\mathrm{CO}_{3} \mathrm{O}_{4}$ nanocube ${ }^{[114]}$. Reproduced from Ref. ${ }^{[114]}$ with permission from the American Chemical Society. SAED: Selected electron diffraction; HRTEM: high-resolution transmission electron microscopy.

corresponding alloying reaction, taking Si as an example, is as follows ${ }^{[125]}$ :

$$
\mathrm{Si}+4.4 \mathrm{Li}^{+}+4.4 e^{-} \leftrightarrow \mathrm{Li}_{4.4} \mathrm{Si}
$$

Due to the atoms of any alloy-type material theoretically holding 4.4 or $3 \mathrm{Li}^{+[5]}$, they exhibit very high specific capacities. For example, silicon $\left(4200 \mathrm{mAh} \cdot \mathrm{g}^{-1}\right)$ is ten times higher than graphite in theoretical capacity $^{[126]}$. It has the highest theoretical capacity of any anode material (with the exception of hydrogen). However, the volume changes greatly during the lithiation reaction, resulting in the formation of a significant outward stress inside the material, which causes the electrode material to be crushed and separated from the collector in serious cases $^{[5]}$. The SEI film also ruptures, exposing a new surface and requiring the continued consumption of lithium to reform the SEI film. Thus, the cycling performance is relatively low ${ }^{[127,128]}$. 
A (1)

As-spun fiber

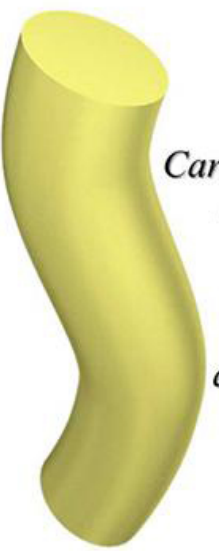

$\mathrm{Fe}(\mathrm{acac})_{3}$-PAN
composite fiber

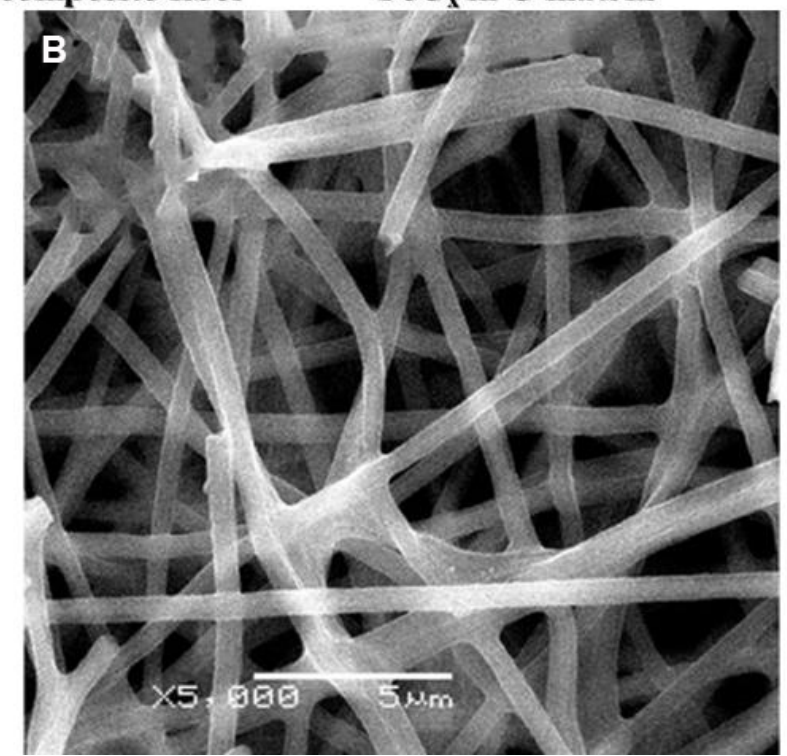

(3) $\mathrm{Fe} @ \mathrm{Fe}_{2} \mathrm{O}_{3}$

(2) $\mathrm{FeO}_{\mathrm{x}}$

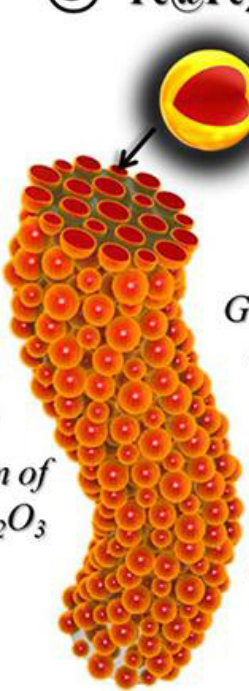

Conversion of Fe into $\mathrm{Fe}_{2} \mathrm{O}_{3}$

Reduction of $\mathrm{FeO}_{x}$ into $\mathrm{Fe}$

Nucleation of amorphous-like $\mathrm{FeO}$

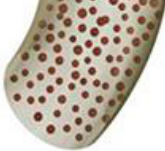

Amorphous-like $\mathrm{FeO}_{\mathrm{x}}$ in $\mathrm{C}$ matrix

$\mathrm{Fe} @ \mathrm{Fe}_{2} \mathrm{O}_{3}$ in $\mathrm{C}$ matrix
(4) $\mathrm{Hollow}_{\mathrm{Fe}_{2}} \mathrm{O}_{3}$

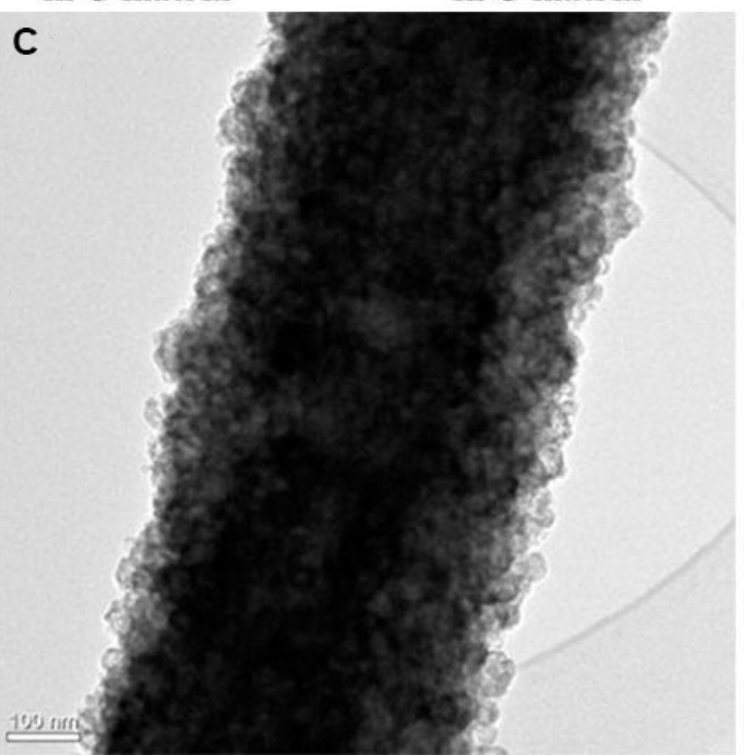

Figure 8. (A) Formation mechanism; (B) SEM image; and (C) TEM image ${ }^{[115]}$ of bubble-nanorod-structured Fe2O3-C composite nanofibers. Reproduced from Ref. ${ }^{[115]}$ with permission from the American Chemical Society.

In response to the above problems, researchers have found that for a single Si particle, there is a critical size of $150 \mathrm{~nm}$, below which it does not break after lithiation ${ }^{[129]}$. Therefore, by reducing the size of Si particles, the inside stress of the electrode material can be released, which reduces the possibility of peeling off from the collector in the reaction process. The pores in porous Si also alleviate the large volume expansion. Various Si nanostructures have been designed to improve their cycling stability, such as nanoparticles $(\mathrm{oD})^{[128,130]}, 1 \mathrm{D}$ structures (nanowires ${ }^{[13,132]}$, nanorods ${ }^{[133,134]}$, and nanotubes ${ }^{[135]}$ ), $2 \mathrm{D}$ thin films ${ }^{[136]}$ and $3 \mathrm{D}$ porous structures ${ }^{[137]}$. In addition, the reasonable design of $\mathrm{Si} / \mathrm{C}$ nanocomposites with special structures is also considered to be an effective method to reduce the capacity attenuation caused by the volume change of Si anodes ${ }^{[138]}$. 
Gu et al. ${ }^{[139]}$ synthesized a Si-CNF composite structure via an electrospinning method and further studied the lithiation process with in situ TEM. The Si particles do not break whether embedded or attached to the carbon nanofibers. Simultaneously, compared with the Si particles attached to the surface, the particles embedded in the CNF show delayed lithiation, which limits the rate capacity of the battery. In addition, the lithiation of particles embedded in CNF produce a high stress field, resulting in cracking of CNF. Therefore, the spatial correlation between Si nanoparticles and carbon nanocomposites is very important when designing carbon-based Si nanoparticle composites.

Ge is a common semiconductor material that belongs to the same main group as Si and has similar chemical properties. Ge has better conductivity and a faster lithium-ion diffusion rate than silicon. The surface oxide layer is thinner and Ge-based anode materials generally have higher coulomb efficiency. The volume expansion of $\mathrm{Ge}$ is isotropic and the anode material is subjected to uniform stress, avoiding the problem of electrode material cracking caused by stress concentration ${ }^{[140]}$. As a rare metal, Ge has a relatively high cost. During battery cycling, Ge and Li ions form an alloy, which can form a Li-rich local region, which explains the high lithium storage performance based on the Ge-based anode electrode. Similar to Si, nanoscale and composite materials are effective improvement measures to solve the inherent shortcomings of Ge.

Yan et al. ${ }^{[141]}$ obtained silver-embedded 3D nanoporous Ge (Ag-np-Ge) by a melt spinning and one-step dealloying method. It was found that when Ge is used as the active material, ensuring a high theoretical capability, the porous network can provide sufficient space for volume expansion and contraction of the material. In addition, the embedded Ag nanoparticles can promote the electron transport rate. Ag-np-Ge presents a high capacity of $953 \mathrm{mAh} \cdot \mathrm{g}^{-1}$ after $100 \mathrm{cycles}$ at $100 \mathrm{~mA} \cdot \mathrm{g}^{-1}$ and an excellent reversible capacity of $522 \mathrm{mAh} \cdot \mathrm{g}^{-1}$ even at $1000 \mathrm{~mA} \cdot \mathrm{g}^{-1}$.

Sn metal is one of the most studied anode materials due to its excellent theoretical capacity (994 $\mathrm{mAh} \cdot \mathrm{g}^{-1}$ ) calculated from the final lithium product of $\mathrm{Li}_{4.4} \mathrm{Sn}^{[142]}$. However, the large $\sim 300 \%$ volume expansion during the lithium process leads to the fracture of the anode material, electrode pulverization, electrical contact failure between the anode materials and conductive additives and an unstable SEI, which limit its commercial application. Jin et al.$^{[143]}$ prepared a novel 3D structured $\mathrm{Sn}$ anode material by a simple method. First, the nanosized $\mathrm{SnO}_{2}$ spheres were heat-treated in a tube furnace $\left(\mathrm{C}_{2} \mathrm{H}_{2} / \mathrm{Ar}\right.$ flow mixing at $\left.400{ }^{\circ} \mathrm{C}\right)$. After heat treatment, the nanosized $\mathrm{SnO}_{2}$ sphere was transformed into a pure Sn bulk material $(\sim 20 \mu \mathrm{m})$, which consisted of Sn nanowires (diameter of $\sim 50 \mathrm{~nm}$ and several microns in length). The obtained samples have a unique $3 \mathrm{D}$ structure with rich voids between the nanowires, which reduce the volume expansion of the $\mathrm{Sn}$ bulk material and ensure good electrical contact between the anode material and the conductive additive. The 3D structured Sn anode material shows a specific reversible capacity of $600 \mathrm{mAh} \cdot \mathrm{g}^{-1}$, with no significant capacity degradation at $0.2 \mathrm{C}$ (compared to the 20 th cycle).

The theoretical specific capacity of $\mathrm{P}$ is $2596 \mathrm{mAh} \cdot \mathrm{g}^{-1}$, which possesses a similar electrochemical reaction mechanism to $\mathrm{Si}^{[144]}$, as follows ${ }^{[145]}$ :

$$
\mathrm{P}+3 \mathrm{Li}^{+}+3 e^{-} \leftrightarrow \mathrm{Li}_{3} \mathrm{P}
$$

There are four allotropes of phosphorus, among which white phosphorus is highly toxic and volatile and is therefore not suitable to be used as an electrode material. In recent decades, there has been little research on violet phosphorus. In contrast, red and black phosphorus have good chemical stability at room temperature and atmospheric pressure, so they are often used as electrode materials ${ }^{[146,147]}$. However, $\mathrm{P}$ and Si share the same challenges. So far, the modification of phosphorus anode materials using carbon materials has become 
the main route to solving these problems ${ }^{[148,149]}$.

Liang et al. ${ }^{[148]}$ synthesized a free-standing flexible $\mathrm{P} / \mathrm{C}$ electrode by encapsulating phosphorous in a dualconducting network of porous multichannel carbon nanofibers and in situ carbon nanotubes (P@PMCNFs/CNTs) [Figure 9A]. The PMCNF/CNT electrode exhibited an outstanding rate performance $\left(601 \mathrm{mAh} \cdot \mathrm{g}^{-1}\right.$ at $\left.3 \mathrm{~A} \mathrm{~g}^{-1}\right)$ and good cycling ability $\left(802.3 \mathrm{mAh} \cdot \mathrm{g}^{-1}\right.$ at $1 \mathrm{~A} \mathrm{~g}^{-1}$ after $\left.500 \mathrm{cycles}\right)$. Yan et al. ${ }^{[149]}$ explored a P@rGO-ACW electrode by constructing phosphorus directly from 3D wood-derived carbon and confining it to a $3 \mathrm{D}$ micro-channel carbon matrix [Figure $9 \mathrm{~B}$ ]. This structure not only buffers the volume expansion of phosphorus in the alloying process, but also shortens the transport distance of lithium ions and improves the conductivity of electrons and ions. Therefore, it has good electrochemical behavior. In addition, Sun et al. ${ }^{[150]}$ proposed a novel P-TiO $@$ @NT composite material. The red phosphorus was modified through the synergistic effect of titanium dioxide and CNTs. The modification not only improved the capacity of $\mathrm{P}$ but also regulated the stress during the expansion process of red phosphorus and avoided structural damage.

As an important alloy-type anode material, Bi metal has a pseudo-layer structure that is similar to graphite. The volume expansion is $74 \%$ due to the formation of a $\mathrm{Li}_{3} \mathrm{Bi}$ alloy, which is significantly smaller than that of $\mathrm{Li}_{4.4} \mathrm{Si}(\sim 400 \%)$ and $\mathrm{Li}_{4.25} \mathrm{Sn}(\sim 257 \%)^{[151-153]}$. Yuan et al. ${ }^{[151]}$ designed an egg-carton-like Bi/C nanocomposite structure [Figure 10A]. From Figure $10 \mathrm{~B}$ and $\mathrm{C}$, the Bi nanoparticles with a diameter of $\sim 20 \mathrm{~nm}$ are placed on micron-sized carbon sheets. The obtained $\mathrm{Bi} / \mathrm{C}$ fractional complex not only inherits the high electrochemical activity of the Bi nanoparticles but also gains additional advantages from the compact micron-size two-dimensional carbon framework, such as high compaction density, medium specific surface area and strong mechanical protection.

In addition, Bi-based transition metal oxides, as potential anode materials for LIBs, have not been extensively studied. Like all other alloy-type anode materials, volume expansion occur during the repeated reaction, which eventually crushes the active material and separates it from the collector, thus reducing the cycling stability ${ }^{[152,153]}$. Liang et al. ${ }^{[153]}$ developed a $\mathrm{Bi}_{2} \mathrm{O}_{2.33} / \mathrm{rGO}$ composite material as an anode material for LIBs. The material has large contact area and unique flexibility. After 600 cycles at $10 \mathrm{C}$, the capacity was still $346 \mathrm{mAh} \cdot \mathrm{g}^{-1}$. Deng et al. ${ }^{[152]}$ prepared a $\mathrm{Bi}_{2} \mathrm{O}_{3} @ \mathrm{rGO}$ nanocomposite by a solvothermal method and introduced chemical bonds [Figure 10D]. The capacity of the anode material is $79 \%$ after 100 times of continuous charge and discharge at $0.1 \mathrm{C}$. Even at $10 \mathrm{C}$, the capacity can reach $270 \mathrm{mAh} \cdot \mathrm{g}^{-1}$. The application of the three typical anode material types in the field of LIBs is summarized in Table 1.

\section{CONCLUSIONS AND PERSPECTIVE}

In this work, intercalation, conversion and alloying anode materials with different electrochemical reaction mechanisms for LIBs are reviewed. The advantages and problems of each type of anode material and the corresponding optimization strategies are described in detail. Intercalation anode materials, such as $\mathrm{Li}_{4} \mathrm{Ti}_{5} \mathrm{O}_{12}$, usually have the disadvantages of low electronic and ionic conductivity, which can be improved by constructing nanostructures or by compounding them with other materials with high conductivity. Conversion and alloying anode materials have the advantages of high specific capacity and high energy density. However, their cycling performance is poor. Their electrochemical performance can be improved by designing their morphology (e.g., nanospheres and nanowires) or by modifying them with graphene, carbon foam and other materials with stable structures and high electrical conductivity.

In general, alloying anode materials represented by $\mathrm{Si}$ and $\mathrm{Sn}$ have become the most attractive anode materials because of their high capacity, but their large volume variation during cycling is the main factor 
Table 1. Electrochemical performance of three typical anode material types

\begin{tabular}{|c|c|c|c|c|}
\hline \multicolumn{2}{|l|}{ Type of anode material } & \multirow{2}{*}{$\frac{\text { Initial capacity }}{365 \mathrm{mAh} \cdot \mathrm{g}^{-1} \text { at } 0.1 \mathrm{C}}$} & \multirow{2}{*}{$\begin{array}{l}\text { Cycling stability } \\
85 \% \text { retention at } 6 \mathrm{C} \text { after } 3000 \text { cycles }\end{array}$} & \multirow{2}{*}{$\begin{array}{l}\text { Ref. } \\
{[61]}\end{array}$} \\
\hline Intercalation-type anode materials & Multichannel graphite & & & \\
\hline & Expanded graphite & $338 \mathrm{mAh} \cdot \mathrm{g}^{-1}\left(0.1 \mathrm{Ag}^{-1}\right)$ & $93 \%$ after 500 cycles $\left(1 \mathrm{~A} \mathrm{~g}^{-1}\right)$ & [63] \\
\hline & $\mathrm{Al}_{2} \mathrm{O}_{3} @$ graphite & $344.85 \mathrm{mAh} \cdot \mathrm{g}^{-1}\left(100 \mathrm{~mA} \mathrm{~g}^{-1}\right)$ & $335 \mathrm{mAh} \cdot \mathrm{g}^{-1}$ after 100 cycles $\left(100 \mathrm{~mA} \mathrm{~g} \mathrm{~g}^{-1}\right)$ & {$[65]$} \\
\hline & N, S-doped graphene & $1636 \mathrm{mAh} \cdot \mathrm{g}^{-1}\left(200 \mathrm{~mA} \mathrm{~g}^{-1}\right)$ & $1090 \mathrm{mAh} \cdot \mathrm{g}^{-1}$ after 500 cycles $\left(200 \mathrm{~mA} \mathrm{~g}^{-1}\right)$ & [72] \\
\hline & P-doped mesoporous C & $622 \mathrm{mAh} \cdot \mathrm{g}^{-1}(0.2 \mathrm{C})$ & $500 \mathrm{mAh} \cdot \mathrm{g}^{-1}$ after 200 cycles (0.5 C) & [73] \\
\hline & $\mathrm{Li}_{5} \mathrm{Cr}_{7} \mathrm{Ti}_{6} \mathrm{O}_{25} @ \mathrm{CeO}_{2}$ & $107.5 \mathrm{mAh} \cdot \mathrm{g}^{-1}(5 \mathrm{C})$ & $100.5 \mathrm{mAh} \cdot \mathrm{g}^{-1}$ after 100 cycles (5 C) & [90] \\
\hline & $\mathrm{Ti}_{2} \mathrm{Nb}_{10} \mathrm{O}_{29} / \mathrm{C}$ & $204 \mathrm{mAh} \cdot \mathrm{g}^{-1}(10 \mathrm{C})$ & $194 \mathrm{mAh} \cdot \mathrm{g}^{-1}$ after 100 cycles (10 C) & [110] \\
\hline \multirow[t]{5}{*}{ Conversion-type anode material } & $\mathrm{NiO}$ & $1219 \mathrm{mAh} \cdot \mathrm{g}^{-1}(0.2 \mathrm{C})$ & $792 \mathrm{mAh} \cdot \mathrm{g}^{-1}$ after 200 cycles (0.2 C) & [121] \\
\hline & $\mathrm{Fe}_{3} \mathrm{O}_{4}$ & $1374 \mathrm{mAh} \cdot \mathrm{g}^{-1}\left(2 \mathrm{Ag}^{-1}\right)$ & $1050 \mathrm{mAh} \cdot \mathrm{g}^{-1}$ after 300 cycles $\left(2 \mathrm{~A} \mathrm{~g}^{-1}\right)$ & [122] \\
\hline & CoP-NPPCS & $837.5 \mathrm{mAh} \cdot \mathrm{g}^{-1}\left(0.2 \mathrm{~A} \mathrm{~g}^{-1}\right)$ & $640 \mathrm{mAh} \cdot \mathrm{g}^{-1}$ after 200 cycles $\left(0.2 \mathrm{~A} \mathrm{~g}^{-1}\right)$ & [117] \\
\hline & $\mathrm{Fe}_{2} \mathrm{O}_{3} / \mathrm{C}$ & $957 \mathrm{mAh} \cdot \mathrm{g}^{-1}\left(1 \mathrm{Ag}^{-1}\right)$ & $812 \mathrm{mAh} \cdot \mathrm{g}^{-1}$ after 300 cycles $\left(1 \mathrm{~A} \mathrm{~g}^{-1}\right)$ & [115] \\
\hline & $\mathrm{Mn}_{2} \mathrm{O}_{3} /$ graphene & $1350 \mathrm{mAh} \cdot \mathrm{g}^{-1}\left(50 \mathrm{~mA} \mathrm{~g}^{-1}\right)$ & $1180 \mathrm{mAh} \cdot \mathrm{g}^{-1}$ after 250 cycles $\left(0.5 \mathrm{~A} \mathrm{~g}^{-1}\right)$ & [116] \\
\hline \multirow[t]{4}{*}{ Alloying-type anode materials } & HF-etching Si & $1700 \mathrm{mAh} \cdot \mathrm{g}^{-1}\left(0.2 \mathrm{~A} \mathrm{~g}^{-1}\right)$ & $959 \mathrm{mAh} \cdot \mathrm{g}^{-1}$ after 300 cycles $\left(0.2 \mathrm{~A} \mathrm{~g}^{-1}\right)$ & [130] \\
\hline & Ag-np-Ge & $\left.1854 \mathrm{mAh} \cdot \mathrm{g}^{-1}(100 \mathrm{~mA} \mathrm{~g})^{-1}\right)$ & $953 \mathrm{mAh} \cdot \mathrm{g}^{-1}$ after 100 cycles $\left(100 \mathrm{~mA} \mathrm{~g}^{-1}\right)$ & [141] \\
\hline & P@PMCNFs/CNTs & $601 \mathrm{mAh} \cdot \mathrm{g}^{-1}\left(3 \mathrm{Ag}^{-1}\right)$ & $802.3 \mathrm{mAh} \cdot \mathrm{g}^{-1}$ after 500 cycles $\left(1 \mathrm{Ag}^{-1}\right)$ & [148] \\
\hline & $\mathrm{Bi} / \mathrm{C}$ & $\left.1057 \mathrm{mAh} \cdot \mathrm{g}^{-1}(100 \mathrm{~mA} \mathrm{~g})^{-1}\right)$ & $523 \mathrm{mAh} \cdot \mathrm{g}^{-1}$ after 100 cycles $\left(100 \mathrm{~mA} \mathrm{~g}^{-1}\right)$ & [151] \\
\hline
\end{tabular}

A
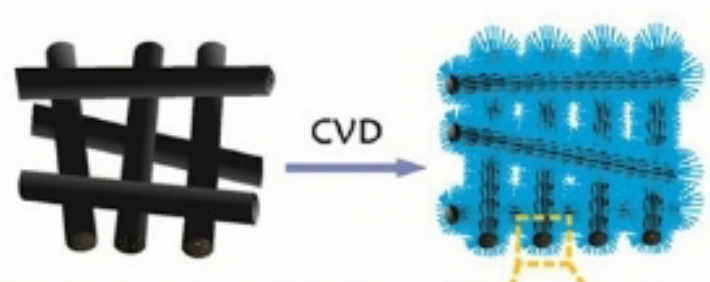

CNTs-assembly

Bare carbon nonwoven fabrics

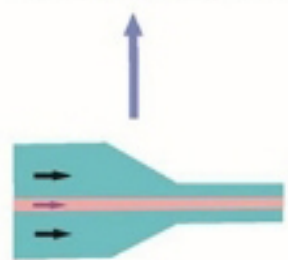

Concentric electrospinning

B

Bulk wood

Activated carbon
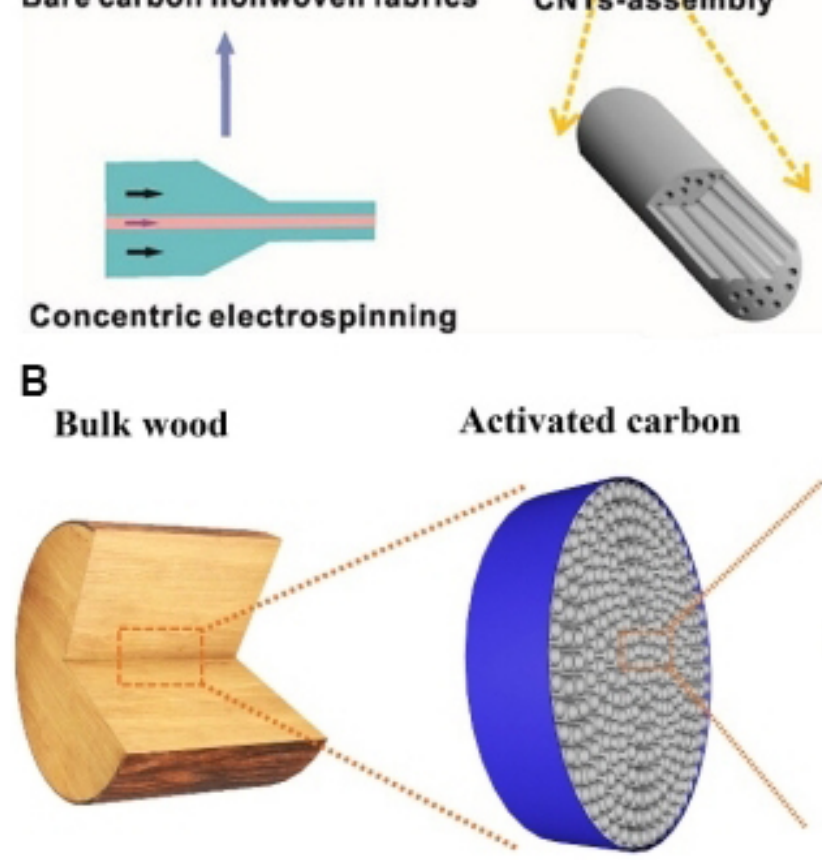

Vaporization condensation
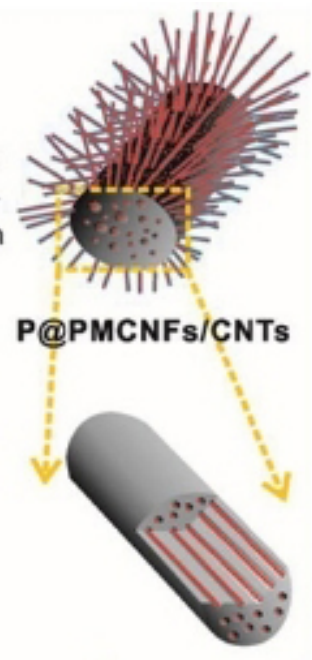

61] 

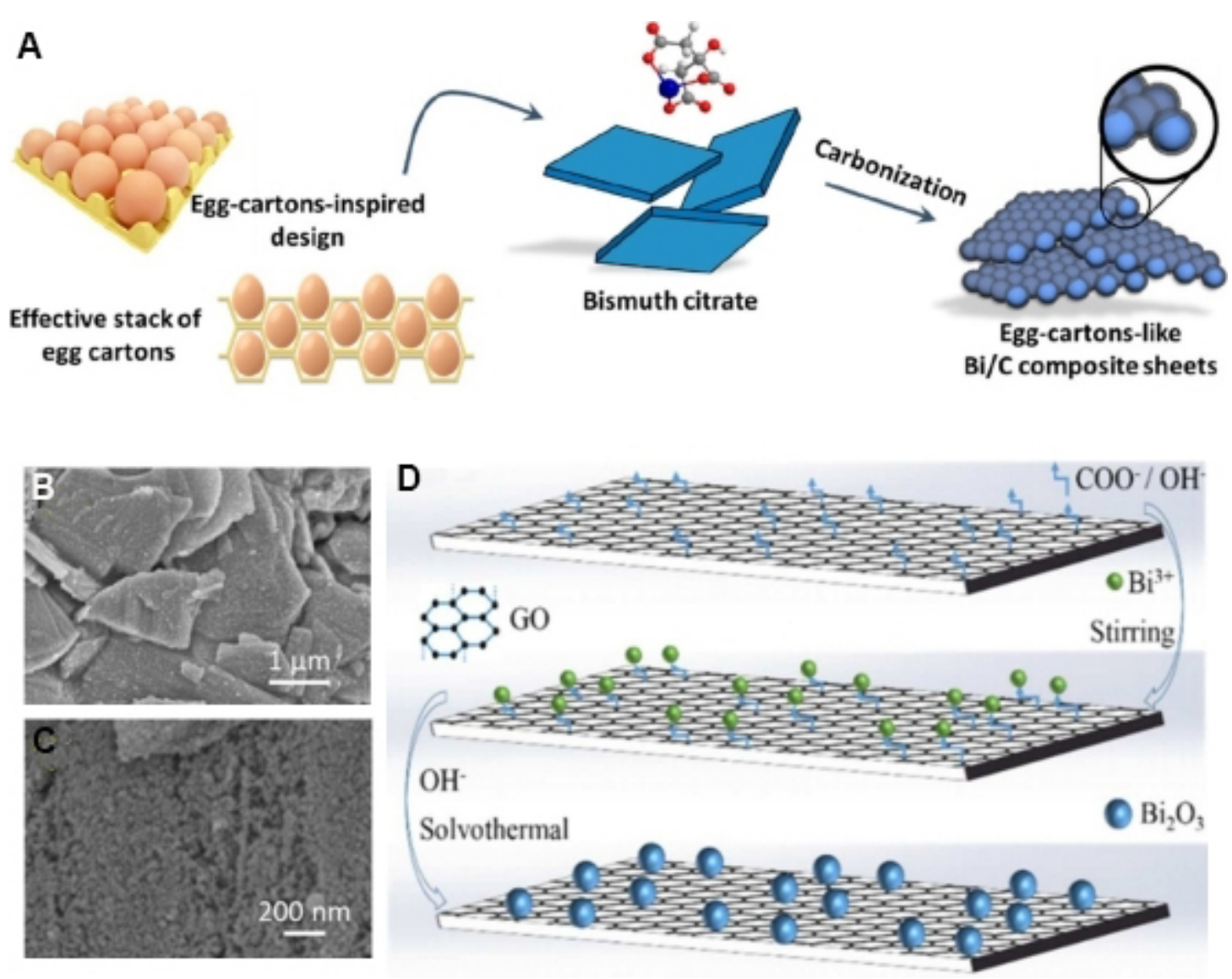

Figure 10. (A) Schematic of $\mathrm{Bi} / \mathrm{C}$ composite sheets. $(\mathrm{B}, \mathrm{C}) \mathrm{SEM}$ images of $\mathrm{Bi} / \mathrm{C}-1000^{[151]}$. (D) Synthetic processes of $\mathrm{Bi}_{2} \mathrm{O}_{3} @ \mathrm{rGO}$ nanocomposite ${ }^{[152]}$. Reproduced from Refs. ${ }^{[151,152]}$ with permission from the American Chemical Society.

that impedes their large-scale application. To solve this problem, the most successful method at present is to conduct nanoscale design and future research should focus on the following aspects. The first is a quantitative understanding of nanoscale design, such as the size dependence of nanostructure properties and the development of effective methods for encapsulating nanostructured materials into electrodes. Second are the factors affecting the first coulombic efficiency, such as the formation and properties of the SEI film. Third, in terms of structural design, it is necessary to further develop advanced in situ and non-in situ characterization techniques, combined with first-principles calculations, to reveal the microstructural changes occurring in the process of lithiation/delithiation and understand the inherent electrochemical mechanism and structural advantages. This will allow the Li storage performance to be further optimized.

Similar to alloying anode materials, conversion anode materials also have the problems of easy pulverization, instability of SEI film and large volume change during cycling. To improve the cycling stability, it is necessary to design nanomaterials to realize the mutual conversion of multiple solid phases. In addition, another challenge of conversion-type anode materials is the large voltage hysteresis $(\sim 1 \mathrm{~V})$ between charge and discharge. An effective method to solve the problem is to select appropriate electrode design and electrolyte type, such as coating a conductive polymer or lithium-ion conductive solid electrolyte layer on the surface of the anode material. 
Anode materials cannot be blindly pursued for high capacity. The synergistic effect of cathode and anode can maximize battery performance. Researchers must design LIB electrodes for overall battery structural stability and high performance and do not need to be limited to current commercial cathode materials. Cathode and anode materials need to be developed together to withstand higher operating voltages and capacities.

Safety is a major consideration in anode design for commercial batteries. Actual battery conditions are often more complex than laboratory test conditions. The structural stability and safety of the battery cannot be ignored. Simultaneously, the selection of materials should avoid toxic and harmful substances. The use of environmentally friendly compounds and composites should be preferred, not only to protect the users but also to reduce the threat to the environment, which is good for recycling.

\section{DECLARATIONS}

\section{Authors' contributions}

Conceptualization, data curation, writing - original draft: Chang $\mathrm{H}$

Conceptualization, data curation, writing - editing: Wu YR

Data curation: Han X

Writing - review and editing, funding acquisition, supervision: Yi TF

\section{Availability of data and materials}

Not applicable.

\section{Financial support and sponsorship}

National Natural Science Foundation of China (No. U1960107), the "333" Talent Project of Hebei Province (No. A202005018), and the Fundamental Research Funds for the Central Universities (No. N2123001).

\section{Conflicts of interest}

All authors declared that there are no conflicts of interest.

\section{Ethical approval and consent to participate}

Not applicable.

\section{Consent for publication}

Not applicable.

\section{Copyright}

(c) The Author(s) 2021.

\section{REFERENCES}

1. Cheng XB, Zhang R, Zhao CZ, Zhang Q. Toward safe lithium metal anode in rechargeable batteries: a review. Chem Rev 2017;117:10403-73. DOI PubMed

2. Albertus P, Babinec S, Litzelman S, Newman A. Status and challenges in enabling the lithium metal electrode for high-energy and low-cost rechargeable batteries. Nat Energy 2018;3:16-21. DOI

3. Chen H, Ling M, Hencz L, et al. Exploring chemical, mechanical, and electrical functionalities of binders for advanced energystorage devices. Chem Rev 2018;118:8936-82. DOI PubMed

4. Winter M, Barnett B, Xu K. Before Li-ion batteries. Chem Rev 2018;118:11433-56. DOI PubMed

5. Zhou L, Zhang K, Hu Z, et al. Recent Developments on and prospects for electrode materials with hierarchical structures for lithiumion batteries. Adv Energy Mater 2018;8:1701415. DOI

6. Zhao C, Liu L, Qi X, et al. Solid-state sodium batteries. Adv Energy Mater 2018;8:1703012. DOI

7. Zhang W, Nie J, Li F, Wang ZL, Sun C. A durable and safe solid-state lithium battery with a hybrid electrolyte membrane. Nano Energy 2018;45:413-9. DOI

8. Tran MK, Rodrigues MF, Kato K, Babu G, Ajayan PM. Deep eutectic solvents for cathode recycling of Li-ion batteries. Nat Energy 
2019;4:339-45. DOI

9. Zou C, Zhang L, Hu X, Wang Z, Wik T, Pecht M. A review of fractional-order techniques applied to lithium-ion batteries, lead-acid batteries, and supercapacitors. J Power Sources 2018;390:286-96. DOI

10. Winslow KM, Laux SJ, Townsend TG. A review on the growing concern and potential management strategies of waste lithium-ion batteries. Resour Conserv Recy 2018;129:263-77. DOI

11. Wu H, Gong Y, Yu Y, Huang K, Wang L. Superior "green" electrode materials for secondary batteries: through the footprint family indicators to analyze their environmental friendliness. Environ Sci Pollut Res Int 2019;26:36538-57. DOI PubMed

12. Yu L, Yu XY, Lou XWD. The design and synthesis of hollow micro-/nanostructures: present and future trends. Adv Mater 2018;30:e1800939. DOI PubMed

13. Young C, Wang J, Kim J, Sugahara Y, Henzie J, Yamauchi Y. Controlled chemical vapor deposition for synthesis of nanowire arrays of metal-organic frameworks and their thermal conversion to carbon/metal oxide hybrid materials. Chem Mater 2018;30:3379-86. DOI

14. Yang C, Chen J, Ji X, et al. Aqueous Li-ion battery enabled by halogen conversion-intercalation chemistry in graphite. Nature 2019;569:245-50. DOI PubMed

15. Xu W, Wang J, Ding F, et al. Lithium metal anodes for rechargeable batteries. Energy Environ Sci 2014;7:513-37. DOI

16. Wu F, Maier J, Yu Y. Guidelines and trends for next-generation rechargeable lithium and lithium-ion batteries. Chem Soc Rev 2020;49:1569-614. DOI PubMed

17. Wei Z, Wang L, Zhuo M, Ni W, Wang H, Ma J. Layered tin sulfide and selenide anode materials for Li- and Na-ion batteries. $J$ Mater Chem A 2018;6:12185-214. DOI

18. Schmuch R, Wagner R, Hörpel G, Placke T, Winter M. Performance and cost of materials for lithium-based rechargeable automotive batteries. Nat Energy 2018;3:267-78. DOI

19. Liu Y, Zhu Y, Cui Y. Challenges and opportunities towards fast-charging battery materials. Nat Energy 2019;4:540-50. DOI

20. Liu J, Bao Z, Cui Y, et al. Pathways for practical high-energy long-cycling lithium metal batteries. Nat Energy 2019;4:180-6. DOI

21. Yan W, Gao X, Jin X, et al. Nonporous Gel electrolytes enable long cycling at high current density for lithium-metal anodes. ACS Appl Mater Interfaces 2021;13:14258-66. DOI PubMed

22. Li M, Lu J, Chen Z, Amine K. 30 years of lithium-ion batteries. Adv Mater 2018;30:e1800561. DOI PubMed

23. Li L, Zheng Y, Zhang S, Yang J, Shao Z, Guo Z. Recent progress on sodium ion batteries: potential high-performance anodes. Energy Environ Sci 2018;11:2310-40. DOI

24. Hwang J, Myung S, Sun Y. Recent progress in rechargeable potassium batteries. Adv Funct Mater 2018;28:1802938. DOI

25. Han F, Westover AS, Yue J, et al. High electronic conductivity as the origin of lithium dendrite formation within solid electrolytes. Nat Energy 2019;4:187-96. DOI

26. Geng P, Zheng S, Tang H, et al. Transition metal sulfides based on graphene for electrochemical energy storage. Adv Energy Mater 2018;8:1703259. DOI

27. Gao Y, Yan Z, Gray JL, et al. Polymer-inorganic solid-electrolyte interphase for stable lithium metal batteries under lean electrolyte conditions. Nat Mater 2019;18:384-9. DOI PubMed

28. Fang R, Chen K, Yin L, Sun Z, Li F, Cheng HM. The regulating role of carbon nanotubes and graphene in lithium-ion and lithiumsulfur batteries. Adv Mater 2019;31:e1800863. DOI PubMed

29. Famprikis T, Canepa P, Dawson JA, Islam MS, Masquelier C. Fundamentals of inorganic solid-state electrolytes for batteries. Nat Mater 2019;18:1278-91. DOI PubMed

30. Ji L, Lin Z, Alcoutlabi M, Zhang X. Recent developments in nanostructured anode materials for rechargeable lithium-ion batteries. Energy Environ Sci 2011;4:2682. DOI

31. Kim S, Seo D, Ma X, Ceder G, Kang K. Electrode materials for rechargeable sodium-ion batteries: potential alternatives to current lithium-ion batteries. Adv Energy Mater 2012;2:710-21. DOI

32. Didier C, Pang WK, Guo Z, Schmid S, Peterson VK. Phase evolution and intermittent disorder in electrochemically lithiated graphite determined using in operando neutron diffraction. Chem Mater 2020;32:2518-31. DOI

33. Li Y, Lu Y, Adelhelm P, Titirici MM, Hu YS. Intercalation chemistry of graphite: alkali metal ions and beyond. Chem Soc Rev 2019;48:4655-87. DOI PubMed

34. Kumar R, Sahoo S, Joanni E, et al. Recent progress in the synthesis of graphene and derived materials for next generation electrodes of high performance lithium ion batteries. Prog Energy Combust Sci 2019;75:100786. DOI

35. Luo Y, Yan Y, Zheng S, Xue H, Pang H. Graphitic carbon nitride based materials for electrochemical energy storage. J Mater Chem A 2019;7:901-24. DOI

36. Zhang W. A review of the electrochemical performance of alloy anodes for lithium-ion batteries. J Power Sources 2011;196:13-24. DOI

37. Verma P, Maire P, Novák P. A review of the features and analyses of the solid electrolyte interphase in Li-ion batteries. Electrochimica Acta 2010;55:6332-41. DOI

38. Reddy AL, Srivastava A, Gowda SR, Gullapalli H, Dubey M, Ajayan PM. Synthesis of nitrogen-doped graphene films for lithium battery application. ACS Nano 2010;4:6337-42. DOI PubMed

39. Marom R, Amalraj SF, Leifer N, Jacob D, Aurbach D. A review of advanced and practical lithium battery materials. J Mater Chem 2011;21:9938. DOI

40. Ding J, Hu W, Paek E, Mitlin D. Review of hybrid ion capacitors: from aqueous to lithium to sodium. Chem Rev 2018;118:6457-98. DOI PubMed 
41. Chen L, Shaw LL. Recent advances in lithium-sulfur batteries. J Power Sources 2014;267:770-83. DOI

42. Nguyen BH, Nguyen VH. Promising applications of graphene and graphene-based nanostructures. Adv Nat Sci: Nanosci Nanotechnol 2016;7:023002. DOI

43. Kleiner K, Ehrenberg H. Challenges considering the degradation of cell components in commercial lithium-ion cells: a review and evaluation of present systems. Top Curr Chem (Cham) 2017;375:54. DOI PubMed

44. Senyshyn A, Mühlbauer M, Dolotko O, Ehrenberg H. Low-temperature performance of Li-ion batteries: the behavior of lithiated graphite. J Power Sources 2015;282:235-40. DOI

45. Persson K, Sethuraman VA, Hardwick LJ, et al. Lithium diffusion in graphitic carbon. J Phys Chem Lett 2010;1:1176-80. DOI

46. Chen M, Wang Z, Wang A, et al. Novel self-assembled natural graphite based composite anodes with improved kinetic properties in lithium-ion batteries. J Mater Chem A 2016;4:9865-72. DOI

47. Zhang $\mathrm{C}$, Cai X, Chen W, et al. 3D porous silicon/N-doped carbon composite derived from bamboo charcoal as high-performance anode material for lithium-Ion batteries. ACS Sustainable Chem Eng 2018;6:9930-9. DOI

48. Nuroniah I, Priyono S, Subhan A, Prihandoko B, Suhandi A, Sohib A. Synthesis and characterization of Al-doped Li4Ti5O12 with Sol Gel method for anode material lithium ion battery. Materials Today: Proceedings 2019;13:65-70. DOI

49. Yin P, Peng H, Xiao Y, Lin T, Lin J. Facile synthesis of an Al-doped carbon-coated $\mathrm{Li}_{4} \mathrm{Ti}_{5} \mathrm{O}_{12}$ anode for high-rate lithium-ion batteries. RSC Adv 2016;6:77151-60. DOI

50. Yi T, Peng P, Han X, Zhu Y, Luo S. Interconnected Co3O4@CoNiO2@PPy nanorod and nanosheet composite grown on nickel foam as binder-free electrodes for Li-ion batteries. Solid State Ionics 2019;329:131-9. DOI

51. Dou Q, Li Y, Ming Ng K. CoO/CoFe2O4 core/shell nanoparticles assembled in carbon sheets as anode materials for lithium ion battery. J Alloys Compds 2019;808:151691. DOI

52. Xiang G, Meng Y, Qu G, et al. Dual-functional NiCo2S4 polyhedral architecture with superior electrochemical performance for supercapacitors and lithium-ion batteries. Sci Bull 2020;65:443-51. DOI

53. Lv G, Zhu B, Li X, et al. Simultaneous perforation and doping of Si nanoparticles for lithium-ion battery anode. ACS Appl Mater Interfaces 2017;9:44452-7. DOI PubMed

54. Jiang Q, Li J, Yuan N, Wu Z, Tang J. Black phosphorus with superior lithium ion batteries performance directly synthesized by the efficient thermal-vaporization method. Electrochimica Acta 2018;263:272-6. DOI

55. Youn DH, Patterson NA, Park H, Heller A, Mullins CB. Facile synthesis of Ge/N-doped carbon spheres with varying nitrogen content for lithium ion battery anodes. ACS Appl Mater Interfaces 2016;8:27788-94. DOI PubMed

56. Liu Z, Song T, Paik U. Sb-based electrode materials for rechargeable batteries. J Mater Chem A 2018;6:8159-93. DOI

57. Zhang H, Eshetu GG, Judez X, Li C, Rodriguez-Martínez LM, Armand M. Electrolyte additives for lithium metal anodes and rechargeable lithium metal batteries: progress and perspectives. Angew Chem Int Ed Engl 2018;57:15002-27. DOI PubMed

58. Zhang X, Cheng X, Chen X, Yan C, Zhang Q. Fluoroethylene carbonate additives to render uniform Li deposits in lithium metal batteries. Adv Funct Mater 2017;27:1605989. DOI

59. Schipper F, Aurbach D. A brief review: Past, present and future of lithium ion batteries. Russ J Electrochem 2016;52:1095-121. DOI

60. Xu J, Dou Y, Wei Z, et al. Recent progress in graphite intercalation compounds for rechargeable metal (Li, Na, K, Al)-Ion batteries. Adv Sci (Weinh) 2017;4:1700146. DOI PubMed PMC

61. Cheng Q, Zhang Y. Multi-channel graphite for high-rate lithium ion battery. J Electrochem Soc 2018;165:A1104-9. DOI

62. Wang Z, Selbach SM, Grande T. Van der Waals density functional study of the energetics of alkali metal intercalation in graphite. RSC Adv 2014;4:3973-83. DOI

63. Son D, Kim J, Raj MR, Lee G. Elucidating the structural redox behaviors of nanostructured expanded graphite anodes toward fastcharging and high-performance lithium-ion batteries. Carbon 2021;175:187-201. DOI

64. Goodenough JB, Park KS. The Li-ion rechargeable battery: a perspective. J Am Chem Soc 2013;135:1167-76. DOI PubMed

65. Kim DS, Kim YE, Kim H. Improved fast charging capability of graphite anodes via amorphous Al2O3 coating for high power lithium ion batteries. J Power Sources 2019;422:18-24. DOI

66. Zheng H, Qu Q, Zhang L, Liu G, Battaglia VS. Hard carbon: a promising lithium-ion battery anode for high temperature applications with ionic electrolyte. RSC Adv 2012;2:4904. DOI

67. Liu J, Xue D. Hollow nanostructured anode materials for Li-ion batteries. Nanoscale Res Lett 2010;5:1525-34. DOI PubMed PMC

68. Malgras V, Tang J, Wang J, et al. Fabrication of nanoporous carbon materials with hard- and soft-templating approaches: a review. $J$ Nanosci Nanotechnol 2019;19:3673-85. DOI PubMed

69. Huang S, Li Z, Wang B, et al. N-doping and defective nanographitic domain coupled hard carbon nanoshells for high performance lithium/sodium storage. Adv Funct Mater 2018;28:1706294. DOI

70. Singh V, Joung D, Zhai L, Das S, Khondaker SI, Seal S. Graphene based materials: past, present and future. Progress in Materials Science 2011;56:1178-271. DOI

71. Huang X, Yin Z, Wu S, et al. Graphene-based materials: synthesis, characterization, properties, and applications. Small 2011;7:1876902. DOI PubMed

72. Ai W, Luo Z, Jiang J, et al. Nitrogen and sulfur codoped graphene: multifunctional electrode materials for high-performance li-ion batteries and oxygen reduction reaction. Adv Mater 2014;26:6186-92. DOI PubMed

73. Wang J, Xia Y, Liu Y, Li W, Zhao D. Mass production of large-pore phosphorus-doped mesoporous carbon for fast-rechargeable lithium-ion batteries. Energy Storage Materials 2019;22:147-53. DOI

74. Zhang B, Kang F, Tarascon J, Kim J. Recent advances in electrospun carbon nanofibers and their application in electrochemical energy storage. Prog Mater Sci Science 2016;76:319-80. DOI 
75. Qie L, Chen WM, Wang ZH, et al. Nitrogen-doped porous carbon nanofiber webs as anodes for lithium ion batteries with a superhigh capacity and rate capability. Adv Mater 2012;24:2047-50. DOI PubMed

76. Wen L, Li F, Cheng HM. Carbon Nanotubes and graphene for flexible electrochemical energy storage: from materials to devices. $A d v$ Mater 2016;28:4306-37. DOI PubMed

77. Zhao MQ, Ren CE, Ling Z, et al. Flexible MXene/carbon nanotube composite paper with high volumetric capacitance. Adv Mater 2015;27:339-45. DOI PubMed

78. Yu D, Goh K, Wang H, et al. Scalable synthesis of hierarchically structured carbon nanotube-graphene fibres for capacitive energy storage. Nat Nanotechnol 2014;9:555-62. DOI PubMed

79. Zhu G, Liu H, Zhuang J, Wang C, Wang Y, Xia Y. Carbon-coated nano-sized $\mathrm{Li}_{4} \mathrm{Ti}_{5} \mathrm{O}_{12}$ nanoporous micro-sphere as anode material for high-rate lithium-ion batteries. Energy Environ Sci 2011;4:4016. DOI

80. Zhao B, Ran R, Liu M, Shao Z. A comprehensive review of $\mathrm{Li}_{4} \mathrm{Ti}_{5} \mathrm{O}_{12}$-based electrodes for lithium-ion batteries: the latest advancements and future perspectives. Mater Sci Eng Rep 2015;98:1-71. DOI

81. Yi T, Yang S, Xie Y. Recent advances of $\mathrm{Li}_{4} \mathrm{Ti}_{5} \mathrm{O}_{12}$ as a promising next generation anode material for high power lithium-ion batteries. J Mater Chem A 2015;3:5750-77. DOI

82. Sun X, Radovanovic PV, Cui B. Advances in spinel $\mathrm{Li}_{4} \mathrm{Ti}_{5} \mathrm{O}_{12}$ anode materials for lithium-ion batteries. New J Chem 2015;39:38-63. DOI

83. Hsieh C, Chen I, Jiang Y, Lin J. Synthesis of spinel lithium titanate anodes incorporated with rutile titania nanocrystallites by spray drying followed by calcination. Solid State Ionics 2011;201:60-7. DOI

84. Ge H, Li N, Li D, Dai C, Wang D. Study on the theoretical capacity of spinel lithium titanate induced by low-potential intercalation. $J$ Phys Chem C 2009;113:6324-6. DOI

85. Zhu Z, Cheng F, Chen J. Investigation of effects of carbon coating on the electrochemical performance of $\mathrm{Li}_{4} \mathrm{Ti}_{5} \mathrm{O}_{12} / \mathrm{C}$ nanocomposites. J Mater Chem A 2013;1:9484. DOI

86. Liu J, Song K, van Aken PA, Maier J, Yu Y. Self-supported $\mathrm{Li}_{4} \mathrm{Ti}_{5} \mathrm{O}_{12}-\mathrm{C}$ nanotube arrays as high-rate and long-life anode materials for flexible Li-ion batteries. Nano Lett 2014;14:2597-603. DOI PubMed

87. Liu Y, Zhao M, Xu H, Chen J. Fabrication of continuous conductive network for $\mathrm{Li}_{4} \mathrm{Ti}_{5} \mathrm{O}_{12}$ anode by Cu-doping and graphene wrapping to boost lithium storage. $J$ Alloys Compds 2019;780:1-7. DOI

88. Khan F, Oh M, Kim JH. N-functionalized graphene quantum dots: Charge transporting layer for high-rate and durable Li4Ti5O12based Li-ion battery. Chem Eng J 2019;369:1024-33. DOI

89. Yan L, Qian S, Yu H, et al. Carbon-enhanced electrochemical performance for spinel $\mathrm{Li}_{5} \mathrm{Cr}_{7} \mathrm{Ti}_{6} \mathrm{O}_{25}$ as a lithium host material. ACS Sustainable Chem Eng 2017;5:957-64. DOI

90. Mei J, Yi TF, Li XY, Zhu YR, Xie Y, Zhang CF. Robust strategy for crafting $\mathrm{Li}_{5} \mathrm{Cr}_{7} \mathrm{Ti}_{6} \mathrm{O}_{25} @ \mathrm{CeO}_{2}$ composites as high-performance anode material for lithium-ion battery. ACS Appl Mater Interfaces 2017;9:23662-71. DOI PubMed

91. Wang Y, Zhu W. Micro/nano-structured $\mathrm{Li}_{4} \mathrm{Ti}_{5} \mathrm{O}_{12}$ as high rate anode material for lithium ion batteries. Solid State Ionics 2020;349:115297. DOI

92. Chen $\mathrm{C}$, Guo $\mathrm{H}$, Zhao Z, et al. A robust strategy for engineering $\mathrm{Li}_{4} \mathrm{Ti}_{5} \mathrm{O}_{12}$ hollow micro-cube as superior rate anode for lithium ion batteries. Electrochimica Acta 2019;293:141-8. DOI

93. Han J, Huang Y, Goodenough JB. New anode framework for rechargeable lithium batteries. Chem Mater 2011;23:2027-9. DOI

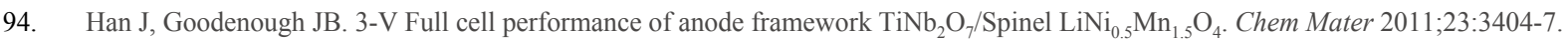
DOI

95. Deng Q, Fu Y, Zhu C, Yu Y. Niobium-based oxides toward advanced electrochemical energy storage: recent advances and challenges. Small 2019;15:e1804884. DOI PubMed

96. Yan L, Rui X, Chen G, Xu W, Zou G, Luo H. Recent advances in nanostructured Nb-based oxides for electrochemical energy storage. Nanoscale 2016;8:8443-65. DOI PubMed

97. Shen P, Zhang B, Wang Y, et al. Nanoscale niobium oxides anode for electrochemical lithium and sodium storage: a review of recent improvements. J Nanostruct Chem 2021;11:33-68. DOI

98. Lim E, Jo C, Kim H, et al. Facile synthesis of Nb2O5@Carbon core-shell nanocrystals with controlled crystalline structure for highpower anodes in hybrid supercapacitors. ACS Nano 2015;9:7497-505. DOI PubMed

99. Yi T, Sari HMK, Li X, et al. A review of niobium oxides based nanocomposites for lithium-ion batteries, sodium-ion batteries and supercapacitors. Nano Energy 2021;85:105955. DOI

100. Zhang C(, Maloney R, Lukatskaya MR, et al. Synthesis and electrochemical properties of niobium pentoxide deposited on layered carbide-derived carbon. J Power Sources 2015;274:121-9. DOI

101. Lou S, Cheng X, Wang L, et al. High-rate capability of three-dimensionally ordered macroporous $\mathrm{T}-\mathrm{Nb}_{2} \mathrm{O}_{5}$ through Li+ intercalation pseudocapacitance. J Power Sources 2017;361:80-6. DOI

102. Hu L, Luo L, Tang L, Lin C, Li R, Chen Y. $\mathrm{Ti}_{2} \mathrm{Nb}_{2 \mathrm{x}} \mathrm{O}_{4+5 \mathrm{x}}$ anode materials for lithium-ion batteries: a comprehensive review. $J$ Mater Chem A 2018;6:9799-815. DOI

103. Lin C, Wang G, Lin S, Li J, Lu L. TiNb6O17: a new electrode material for lithium-ion batteries. Chem Commun (Camb) 2015;51:8970-3. DOI PubMed

104. Li H, Zhang Y, Tang Y, et al. TiNb2O7 nanowires with high electrochemical performances as anodes for lithium ion batteries. Appl Surf Sci 2019;475:942-6. DOI

105. Li H, Shen L, Wang J, et al. Three-dimensionally ordered porous $\mathrm{TiNb}_{2} \mathrm{O}_{7}$ nanotubes: a superior anode material for next generation hybrid supercapacitors. J Mater Chem A 2015;3:16785-90. DOI 
106. Gao J, Cheng X, Lou S, et al. Self-doping $\mathrm{Ti}_{1}-\mathrm{Nb}_{2}+\mathrm{O}_{7}$ anode material for lithium-ion battery and its electrochemical performance. $J$ Alloys Compds 2017;728:534-40. DOI

107. Yu Z, Waclawik ER, Wang Z, Gu X, Yuan Y, Zheng Z. Dual modification of $\mathrm{TiNb}_{2} \mathrm{O}_{7}$ with nitrogen dopants and oxygen vacancies for selective aerobic oxidation of benzylamine to imine under green light. J Mater Chem A 2017;5:4607-15. DOI

108. Wan G, Yang L, Shi S, Tang Y, Xu X, Wang G. $\mathrm{Ti}_{2} \mathrm{Nb}_{10} \mathrm{O}_{29}$ microspheres coated with ultrathin N-doped carbon layers by atomic layer deposition for enhanced lithium storage. Chem Commun (Camb) 2019;55:517-20. DOI PubMed

109. Lyu H, Li J, Wang T, et al. Carbon coated porous titanium niobium oxides as anode materials of lithium-ion batteries for extreme fast charge applications. ACS Appl Energy Mater 2020;3:5657-65. DOI

110. Liu G, Jin B, Zhang R, et al. Synthesis of $\mathrm{Ti}_{2} \mathrm{Nb}_{10} \mathrm{O}_{29} / \mathrm{C}$ composite as an anode material for lithium-ion batteries. Int J Hydrogen Energy 2016;41:14807-12. DOI

111. Ashish A, Arunkumar P, Babu B, Manikandan P, Sarang S, Shaijumon M. $\mathrm{TiNb}_{2} \mathrm{O}_{7} /$ Graphene hybrid material as high performance anode for lithium-ion batteries. Electrochimica Acta 2015;176:285-92. DOI

112. Shi Y, Wang JZ, Chou SL, et al. Hollow structured Li3VO4 wrapped with graphene nanosheets in situ prepared by a one-pot template-free method as an anode for lithium-ion batteries. Nano Lett 2013;13:4715-20. DOI PubMed

113. Shi Y, Gao J, Abruña HD, et al. The mechanism of the one-step synthesis of hollow-structured $\operatorname{Li}(3) \operatorname{VO}(4)$ as an anode for lithiumion batteries. Chemistry 2014;20:5608-12. DOI PubMed

114. Luo L, Wu J, Xu J, Dravid VP. Atomic resolution study of reversible conversion reaction in metal oxide electrodes for lithium-ion battery. ACS Nano 2014;8:11560-6. DOI PubMed

115. Cho JS, Hong YJ, Kang YC. Design and synthesis of bubble-nanorod-structured $\mathrm{Fe}_{2} \mathrm{O}_{3}$-carbon nanofibers as advanced anode material for li-ion batteries. ACS Nano 2015;9:4026-35. DOI PubMed

116. Yuan $\mathrm{S}$, Chen W, Zhang L, et al. Nitrogen-doped graphene-buffered $\mathrm{Mn}_{2} \mathrm{O}_{3}$ nanocomposite anodes for fast charging and high discharge capacity lithium-ion batteries. Small 2019;15:1903311. DOI PubMed

117. Bai J, Xi B, Mao H, et al. One-step construction of N,P-codoped porous carbon sheets/CoP hybrids with enhanced lithium and potassium storage. Adv Mater 2018;30:e1802310. DOI PubMed

118. Dong Y, Li Y, Shi H, et al. Graphene encapsulated iron nitrides confined in 3D carbon nanosheet frameworks for high-rate lithium ion batteries. Carbon 2020;159:213-20. DOI

119. Cabana J, Monconduit L, Larcher D, Palacín MR. Beyond intercalation-based Li-ion batteries: the state of the art and challenges of electrode materials reacting through conversion reactions. Adv Mater 2010;22:E170-92. DOI PubMed

120. Lu Y, Yu L, Lou XW. Nanostructured conversion-type anode materials for advanced lithium-ion batteries. Chem 2018;4:972-96. DOI

121. Wang C, Zhao Y, Su D, et al. Synthesis of NiO Nano octahedron aggregates as high-performance anode materials for lithium ion batteries. Electrochimica Acta 2017;231:272-8. DOI

122. Choi SH, Kang YC. Fe3O4-decorated hollow graphene balls prepared by spray pyrolysis process for ultrafast and long cycle-life lithium ion batteries. Carbon 2014;79:58-66. DOI

123. Zhang J, Chu R, Chen Y, et al. MOF-derived transition metal oxide encapsulated in carbon layer as stable lithium ion battery anodes. J Alloys Compds 2019;797:83-91. DOI

124. Yu X, Yu L, Lou XWD. Metal sulfide hollow nanostructures for electrochemical energy storage. Adv Energy Mater 2016;6:1501333. DOI

125. Kummer M, Badillo JP, Schmitz A, et al. Silicon/polyaniline nanocomposites as anode material for lithium ion batteries. $J$ Electrochem Soc 2013;161:A40-5. DOI

126. Luo Z, Xiao Q, Lei G, Li Z, Tang C. Si nanoparticles/graphene composite membrane for high performance silicon anode in lithium ion batteries. Carbon 2016;98:373-80. DOI

127. Kim H, Lee E, Sun Y. Recent advances in the Si-based nanocomposite materials as high capacity anode materials for lithium ion batteries. Mater Today 2014;17:285-97. DOI

128. Su X, Wu Q, Li J, et al. Silicon-based nanomaterials for lithium-ion batteries: a review. Adv Energy Mater 2014;4:1300882. DOI

129. Liu XH, Zhong L, Huang S, Mao SX, Zhu T, Huang JY. Size-dependent fracture of silicon nanoparticles during lithiation. ACS Nano 2012;6:1522-31. DOI PubMed

130. Zuo X, Xia Y, Ji Q, et al. Self-templating construction of 3D hierarchical macro-/mesoporous silicon from 0D silica nanoparticles. ACS Nano 2017;11:889-99. DOI PubMed

131. Chan CK, Peng H, Liu G, et al. High-performance lithium battery anodes using silicon nanowires. Nat Nanotechnol 2008;3:31-5. DOI PubMed

132. Cui LF, Ruffo R, Chan CK, Peng H, Cui Y. Crystalline-amorphous core-shell silicon nanowires for high capacity and high current battery electrodes. Nano Lett 2009;9:491-5. DOI PubMed

133. Tao H, Fan L, Qu X. Facile synthesis of ordered porous Si@C nanorods as anode materials for Li-ion batteries. Electrochimica Acta 2012;71:194-200. DOI

134. Wang J, Meng X, Fan X, Zhang W, Zhang H, Wang C. Scalable synthesis of defect abundant si nanorods for high-performance li-ion battery anodes. ACS Nano 2015;9:6576-86. DOI PubMed

135. Park MH, Kim MG, Joo J, et al. Silicon nanotube battery anodes. Nano Lett 2009;9:3844-7. DOI PubMed

136. Bensalah N, Kamand FZ, Zaghou M, Dawoud HD, Tahtamouni TA. Silicon nanofilms as anode materials for flexible lithium ion batteries. Thin Solid Films 2019;690:137516. DOI

137. McDowell MT, Lee SW, Nix WD, Cui Y. 25th anniversary article: understanding the lithiation of silicon and other alloying anodes 
for lithium-ion batteries. Adv Mater 2013;25:4966-85. DOI PubMed

138. Terranova ML, Orlanducci S, Tamburri E, Guglielmotti V, Rossi M. Si/C hybrid nanostructures for Li-ion anodes: an overview. $J$ Power Sources 2014;246:167-77. DOI

139. Gu M, Li Y, Li X, et al. In situ TEM study of lithiation behavior of silicon nanoparticles attached to and embedded in a carbon matrix. ACS Nano 2012;6:8439-47. DOI PubMed

140. Cheng H, Shapter JG, Li Y, Gao G. Recent progress of advanced anode materials of lithium-ion batteries. J Energy Chem 2021;57:451-68. DOI

141. Yan Y, Liu Y, Zhang Y, Qin C, Bakenov Z, Wang Z. Improving the cycling stability of three-dimensional nanoporous Ge anode by embedding Ag nanoparticles for high-performance lithium-ion battery. J Colloid Interface Sci 2021;592:103-15. DOI PubMed

142. Wang X, Zhu S, Dong X, Huang H, Qi M. Ionic liquid assisted electrospinning synthesis for ultra-uniform Sn@ mesoporous carbon nanofibers as a flexible self-standing anode for lithium ion batteries. J Alloys Compds 2021;866:158984. DOI

143. Jin Z, Ben L, Yu H, Zhao W, Huang X. A facile method to synthesize 3D structured Sn anode material with excellent electrochemical performance for lithium-ion batteries. Progress in Natural Science: Materials International 2020;30:456-60. DOI

144. Zhang C, Wang X, Liang Q, et al. Amorphous phosphorus/nitrogen-doped graphene paper for ultrastable sodium-ion batteries. Nano Lett 2016;16:2054-60. DOI PubMed

145. Chen X, Qiu J, Wang Y, et al. Cactus-like iron diphosphide@carbon nanotubes composites as advanced anode materials for lithiumion batteries. Electrochimica Acta 2018;259:321-8. DOI

146. Li X, Wang X, Sun J. Recent progress in the carbon-based frameworks for high specific capacity anodes/cathode in lithium/sodium ion batteries. New Carbon Materials 2021;36:106-16. DOI

147. Liu W, Zhi H, Yu X. Recent progress in phosphorus based anode materials for lithium/sodium ion batteries. Energy Storage Materials 2019;16:290-322. DOI

148. Liang S, Pei X, Jiang W, et al. Free-standing dual-network red phosphorus@porous multichannel carbon nanofibers/carbon nanotubes as a stable anode for lithium-ion batteries. Electrochimica Acta 2019;322:134696. DOI

149. Yan Y, Xu H, Peng C, Zhang P, Yang J, Zheng S. 3D phosphorus-carbon electrode with aligned nanochannels promise high-arealcapacity and cyclability in lithium-ion battery. Appl Surf Sci 2019;489:734-40. DOI

150. Sun L, Zhang Y, Si H, et al. TiO2-modified red phosphorus nanosheets entangled in carbon nanotubes for high performance lithium ion batteries. Electrochimica Acta 2019;297:319-27. DOI

151. Yuan H, Jin Y, Chen X, Lan J, Yu Y, Yang X. Large-scale fabrication of egg-carton-inspired Bi/C composite toward high volumetric capacity and long-life lithium ion batteries. ACS Sustainable Chem Eng 2019;7:6033-42. DOI

152. Deng Z, Liu T, Chen T, et al. Enhanced electrochemical performances of $\mathrm{Bi}_{2} \mathrm{O}_{3} / \mathrm{rGO}$ nanocomposite via chemical bonding as anode materials for lithium ion batteries. ACS Appl Mater Interfaces 2017;9:12469-77. DOI PubMed

153. Liang H, Liu X, Gao D, Ni J, Li Y. Reduced graphene oxide decorated with Bi2O2.33 nanodots for superior lithium storage. Nano Res 2017;10:3690-7. DOI 